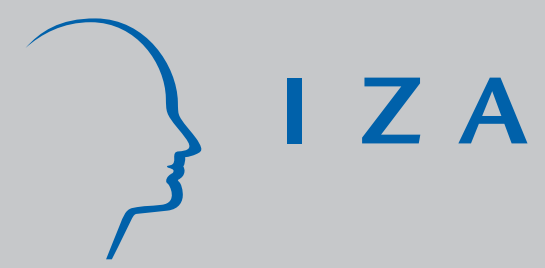

IZA DP No. 5060

Disclosure, Trust and Persuasion in Insurance Markets

David de Meza

Bernd Irlenbusch

Diane Reyniers

July 2010 


\title{
Disclosure, Trust and Persuasion in Insurance Markets
}

\author{
David de Meza \\ London School of Economics \\ Bernd Irlenbusch \\ London School of Economics \\ and IZA \\ Diane Reyniers \\ London School of Economics
}

Discussion Paper No. 5060
July 2010

IZA

P.O. Box 7240

53072 Bonn

Germany

Phone: +49-228-3894-0

Fax: +49-228-3894-180

E-mail: iza@iza.org

\begin{abstract}
Any opinions expressed here are those of the author(s) and not those of IZA. Research published in this series may include views on policy, but the institute itself takes no institutional policy positions.

The Institute for the Study of Labor (IZA) in Bonn is a local and virtual international research center and a place of communication between science, politics and business. IZA is an independent nonprofit organization supported by Deutsche Post Foundation. The center is associated with the University of Bonn and offers a stimulating research environment through its international network, workshops and conferences, data service, project support, research visits and doctoral program. IZA engages in (i) original and internationally competitive research in all fields of labor economics, (ii) development of policy concepts, and (iii) dissemination of research results and concepts to the interested public.
\end{abstract}

IZA Discussion Papers often represent preliminary work and are circulated to encourage discussion. Citation of such a paper should account for its provisional character. A revised version may be available directly from the author. 


\section{ABSTRACT}

\section{Disclosure, Trust and Persuasion in Insurance Markets}

This high-stakes experiment investigates the effect on buyers of mandatory disclosures concerning an insurance policy's value for money (the claims ratio) and the seller's commission. These information disclosures have virtually no effect despite most buyers claiming to value such information. Instead, our data reveal that whether the subject is generally trusting plays an important role. Trust is clearly associated with greater willingness to pay for insurance. Unlike in previous work, trust in our setting is not about obligations being fulfilled. The contract is complete, simple and the possibility of breach is negligible. However, as for much B2C insurance marketing, face-to-face selling plays a crucial role in our experimental design. Trusting buyers are more suggestible, so take advice more readily and buy more insurance, although they are no more risk averse than the uninsured. Moreover, trusting buyers feel less pressured by sellers, and are more confident in their decisions which suggests that they are easier to persuade. Therefore, in markets where persuasion is important, public policy designed to increase consumer information is likely to be ineffective.

JEL Classification: $\quad$ C91, G22, M30

Keywords: insurance selling, trust, persuasion

Corresponding author:

Bernd Irlenbusch

Professor of Corporate Development and Business Ethics

University of Cologne

Herbert-Lewin Str. 2

50931 Cologne

Germany

E-mail: bernd.irlenbusch@uni-koeln.de

\footnotetext{
* We are grateful to the Financial Services Authority (FSA) for funding. The FSA is an independent non-governmental body that regulates the financial services industry in the UK. This research was commissioned by the FSA. The data was collected by the market research company ORC at different venues around the UK.
} 
"If I listened long enough to you

I'd find a way to believe that it's all true"

Tim Hardin

\section{Introduction}

In December 2007, the Financial Service Authority (FSA) published new rules to regulate insurance selling in the UK. The redesigned Insurance Conduct of Business Sourcebook (ICOBS) was intended to meet the FSA's statutory objective to help consumers achieve a fair deal. As Dan Waters, FSA Director of Retail Policy and Themes, said in the FSA's press release ${ }^{1}$ : "ICOBS is another important achievement in more principles-based regulation. [...] In a few areas [...], like payment protection insurance (PPI), we have responded to continuing market failures and consumer detriment by introducing carefully targeted rules to help ensure that consumers achieve a fair deal”. The sale of payment protection insurance (PPI) and mortgage protection insurance (MPI) in the UK has indeed aroused much controversy. These policies are typically sold as secondary products by lenders, making it hard for buyers to shop around. Clients may not realize that the loan and insurance purchases can be separated and that there are competitive insurance products readily available. In addition, the policies typically have many exclusions that buyers may not be aware of. Selling pressure may result in buyers purchasing inappropriate policies at excessive premiums. It is certainly true that PPI policies offer lower payout ratios (the fraction of premium income paid out to policy holders) than other kinds of insurance, some $15 \%$ here compared to $84 \%$ for home contents insurance (OFT 2006) $)^{2}$.

\footnotetext{
${ }^{1}$ FSA press release: "FSA cuts back on detailed insurance selling rules but tightens up where customers are not being treated fairly”, 18 December 2007.

${ }^{2}$ The Office of Fair Trading (OFT 2006, p. 96-97) remarks in the payment protection insurance context "Where customers are well informed, they are in a position to make efficient choices...in the absence of such information, markets will fail to work efficiently." OFT (2006, p. 139) also reports anecdotal evidence of "pressurised selling due to lenders' bonus schemes". In October 2006 the OFT Chief Executive John Fingleton said: "Following the work we have undertaken it is clear that many consumers are failed by PPI insurance which gives them a poor deal and often less protection than they think."
} 
ICOBS now includes, for example, a new standard to ensure better oral disclosure of key information about policies. However, does more (oral) disclosure of information result in different and better decisions? Can salesmanship counter formal disclosure requirements in face-to-face insurance selling? This paper reports on an experiment designed to shed light on these questions in the context of income and loan payment protection insurance.

According to conventional economic analysis, the question does not require much investigation. Individuals take optimal Bayesian decisions. The provision of extra relevant information improves decisions, so a government should ensure that it is delivered in easily digestible form as long as this can be cheaply accomplished. For example, revelation of conflicts of interest of the salesperson due to rewards based on the number of signed insurance contracts, should lead customers to be more suspicious.

In contrast, much research in psychology and more recently in behavioral economics challenges the idea that more information is always better. Attention is a scarce resource and processing power is limited. More information may deflect attention from what is really important. A pervasive finding (e.g., Kruschke and Johansen 1999) is that cue competition occurs: more salient cues weaken the effects of less salient ones, and the presence of irrelevant cues causes subjects to make less use of relevant cues. Introducing additional accurate information may therefore lead to worse outcomes.

Sellers' disclosure of information might even increase rather than decrease trust and thereby lead customers into a relaxation of vigilance. Mercer (2005), for example, finds that at least in the short-term, more disclosure has a positive effect on management's reporting credibility in the eyes of investors, especially when negative information is disclosed. Cain, Loewenstein, and Moore (2005) argue that "there is at least suggestive evidence that people tend to be naturally trusting and credulous toward their own advisors. In the domain of medicine, for example, research shows that while many people are ready to acknowledge that doctors generally might be affected by conflicts of interest, few can imagine that their own doctors would be affected (Gibbons et al. 1998).”

Attitudes of this sort feature in what is probably the most famous experiment in social science. Stanley Milgram (1963) found that despite considerable misgivings, most people are prepared to administer severe electric shocks to strangers if asked to by an authority 
figure. According to Mixon (1971, 1972), it is trust that makes people accede to such requests. Trusting subjects do what they are told. The economics literature has a slightly different perspective. As exemplified by the trust game of Berg, Dickhaut and McCabe (1995), the specific focus is on beliefs about the future behavior of those you interact with. Trusting people make themselves vulnerable to subsequent exploitation because they do not expect to be taken advantage of. Thus, trusting (and trustworthy) societies solve the hold-up problem in all its manifestations and prosper. As the Milgram experiment indicates, this is not the only way trust may have an influence. Consider the task of a seller persuading people to buy insurance. Much of the pitch is not reassurance the product will perform as promised, but persuading the buyer that they need what is on offer. And indeed our high-stakes experiment finds that a generalized capacity to trust others, though uncorrelated with risk preferences, is an important determinant of whether subjects buy insurance when fulfillment of the contractual terms is not an issue. Even telling buyers that the sellers are on commission makes little difference to their behavior. ${ }^{3}$ Our buyer subjects were of a full range of ages and were seeking or had recently obtained unsecured loans outside the experiment. The experiment offered the prospect of substantial sums of money and/or valuable items but there was a well-defined chance, determined by the throw of a die, that these outcomes would not materialize. Subjects could take out insurance against the chance of loss. The buyers' choices could have major consequences for them. The 25 seller subjects all had experience of retail selling and selling on commission. They received performance pay and in their sessions with buyers they followed the same prescribed script, but at two points had the opportunity to make a one or two minute personalized "pitch".

The results show that willingness to pay for insurance depends on the extent to which the buyer trusts people in general and on the extraversion of the seller. Trust is though uncorrelated with risk preference so it is not picking up a taste for safety. ${ }^{4}$

3 This resembles the cursed equilibrium of Eyster and Rabin (2005) in which players do not fully infer the information held by others from their actions. Our buyers are cursed to the extent they do not question the motivation for sellers' advice.

4 In a laboratory experiment Eckel and Wilson (2004) also find no statistical relationship between behavioral risk measures and decisions to trust. 
In our experiment the contract is simple, with the probability of loss known precisely so there is no issue of trusting or believing that the contractual terms will be fulfilled. Trusting individuals appear to accept the recommendation of the partisan seller more readily. They are also more confident that they have made the correct choice and they feel less pressured by the sellers. There is some support for our findings from decisions taken outside the experiment: Buyers with a trusting nature are more likely to actually have purchased mortgage protection insurance (MPI). The high mark-ups of MPIs suggest that sellers take advantage of buyer trust by pushing up premiums. Our results indicate that information provision is unlikely to offset these effects.

Most subjects thought it was important to have information on the sellers' incentives and the payout ratio of the policy to take sensible decisions. Presumably, they are aware of the possibility of being influenced by biased sellers. Yet willingness to pay for insurance is unaffected by the disclosure of these two pieces of information. The personal factor is too strong. Compulsory disclosure of sellers' incentives and payout ratios are both ineffective, even if sellers can be relied on to comply with disclosure.

These results provide mixed support for the dictum that insurance is sold not bought. The characteristics of both the seller and the buyer matter. As in standard economic analysis, the higher the premium, the lower is demand. Purchase does though reflect more than intrinsic risk aversion and value at risk. Trusting subjects appear willing to believe that in recommending insurance, sellers are selfless. In our experiment the stakes are high, the product is well specified and sellers have limited opportunity to exert an influence. Nevertheless, there are large effects.

Empirical evidence on the effects of disclosure is sparse. Cain, Loewenstein, and Moore (2005) appear to be the first to systematically investigate disclosure of interest. In a laboratory experiment subjects are paid for the precision of the estimates of an amount of money (coins) in a jar. They see the jar only from a distance and for a short period of time. They can, however, take into account advice of a second group of subjects, the advisors. Advisors are better informed because they can inspect the jar more closely and they are given more time. Advice is not provided face-to-face but the advisors' views are transmitted on written forms. In three experimental treatments the incentives for the 
advisors and disclosure of information are varied. In a first treatment, the advisors are paid for how closely the subjects guess the total amount of money in the jar. In a second and third treatment, the advisors are paid more the more the estimates exceed the true amount. While in the first and second treatment (mis)alignment of incentives is not revealed to the estimators, misalignment is disclosed in the third treatment. It turns out that advisors respond to incentives, i.e., their advice increases by 22\% when they are paid according to high estimates. Advice is even more biased (47\%) when incentives are disclosed. The researchers suggest that this surprising result might partly be explained by "moral licensing": disclosing of interest might reduce advisor's feelings of guilt about giving misleading advice since buyers should have expected that advice is actually biased. Providing advisors with a "moral license" might lead them to bias advice further than without disclosure. In fact, estimators tend to discount for the higher advice in the case of disclosure but their adjustment is not sufficient. ${ }^{5}$ The estimate of the subjects in the disclosure treatment is 28 percent higher than in the treatment with incentives of advisors and estimators being aligned. As a result estimators earn less money when conflicts of interest are disclosed than when they are not. Advisors make more money with disclosure than without. Thus, disclosure in this (stylized) experiment benefits the providers of information but not the recipients. These findings are confirmed in a followup study by Koch and Schmidt (2010) who conjecture that repetition and reputation might reduce the negative effects of disclosure. These studies are, however, not designed to investigate the role of trust when disclosing information.

Lacko and Pappalardo (2004) report on a questionnaire study for the US Federal Trade Commission (FTC) on a planned mortgage broker compensation disclosure. Recent mortgage customers are shown costs information about two hypothetical mortgage loans

5 This finding is in line with an empirical study by Malmendier and Shanthikumar (2007) who analyze how investors respond to recommendation by analysts. They show that analysts' forecasts are extremely biased upward and that small investors (in contrast to large investors) are subject to persuasion. Small investors do not discount for the additional distortions due to analyst affiliation. Evidence on the intricacies of persuasion comes from research on consumer credit marketing. Bertrand et al. (2010) find that showing fewer example loans, not suggesting a particular use for the loan, or including a photo of an attractive woman increases loan demand by about as much as a $25 \%$ reduction in the interest rate. Their findings also suggest that advertising content persuades by appealing to intuition rather than reason. For an overview of empirical evidence on persuasion see Della Vigna and Gentzkow (2010). Studies from psychology show that emotions, for example, fear induced by insurance sellers about possible negative future contingencies, can considerably alter the persuasive impact of messages (De Steno et al. 2004). 
and are asked to identify which of the two would cost them less and which loan they would choose if they were shopping for a mortgage. Answers are not incentivized. In different treatments different versions of information disclosure that actually have been proposed in the political arena, are provided for one of the loans. All tested disclosure versions result in significant consumer confusion about loan costs. Disclosure leads a significant proportion of borrowers to mistakenly choose more expensive loans. However, disclosure of information does not always lead to confusion of customers, especially if it is provided to reduce biases as is shown by Bertrand and Morse (2009). They use a randomized field trial to evaluate how various kinds of information disclosure about the costs of payday loans impact on people's decision to borrow from pay day lenders. They are able to show that some kind of information that helps people to avoid narrow decision frames, i.e., to focus more on the cost of using payday loans for longterm finance, and in particular information that reinforces the adding-up effect over pay cycles, reduces the take-up of payday loans by about 10 percent.

In this paper we argue that disclosure of conflict of interest and disclosure of information on payout ratios has virtually no impact in face-to-face insurance selling. One of the reasons is that experienced sellers can exploit the fact that to a considerable extent, consumers of financial products believe what they are told. ${ }^{6}$ They are trusting. ${ }^{7}$ We don't ask for this claim be taken on trust. The next section of the paper explains the experimental design. Then results are analyzed. After a discussion on generalized trust and openness to persuasion, conclusions are drawn.

6 A number of papers, for example Ariely, Loewenstein, and Prelec (2003) and Bertrand et al. (2010) find evidence that preferences are constructed though do not explicitly examine the role of trust. Mullainathan, Schwartzstein and Shleifer (2008) argue that uninformative messages are effective in financial services because consumers inappropriately transfer some property of an entity the seller puts in the mind of the buyer (say a grandfather and grandson fishing) to a financial product. This paper provides evidence that such unsubstantiated claims are believed. Why they should be is probably a topic for evolutionary psychology. Perhaps in the small groups with limited migration that characterised hunter gatherer society untruths would normally be discovered and be sure to rebound on the perpetrator. Developing an aversion to lying may then, as found by Gneezy (2005), be advantageous. Because it pays to be truthful, it is rational to believe what people say. This contrasts with the rational scepticism approach of Milgrom (2008).

7 A number of papers in the marketing literature identify characteristics of successful sellers (for a review see Swan, Bowers, and Richardson 1998). In the context of financial services, Georges and Guenzi (2009) find that likability and customer orientation increase a client's trust in a salesperson and clients who trust the seller say they are more likely to return. This study, like the others does not though identify what makes buyers receptive. 


\section{Experimental Design and Procedure}

Subjects comprised potential buyers and sellers of insurance. All subjects were recruited by ORC, a market research company, who also administered the experiment. The 214 buyers were members of the general public who had either recently obtained an unsecured loan or were seeking one. ${ }^{8}$ All 25 sellers had experience of commission selling, though not of marketing of financial products. The experiment was conducted on two successive Saturdays in September 2007 in 5 venues around the UK. Each seller dealt with 7 to 9 buyers. Sellers were paid an attendance fee of $£ 180$ and were also in receipt of performance pay, the nature of which will be described later.

Buyers were paid an attendance fee of $£ 25$ and were told that they also stood to win up to $£ 5,750$ in cash or a valuable prize. Once recruited, buyers were sent through the post an illustrated leaflet describing 10 prizes and were told that each was valued at about £2,500. These items included a motorbike, Rolex watches, holidays, a plasma TV, and so forth. Buyers were told that they could win one of these items and asked to think about which one they would prefer. When they arrived at the venue they were asked which prize they had chosen.

Buyers met a seller face-to-face. For the key instructions sellers followed a script. As an example, the script for one of the treatments is reproduced in Appendix A. The corresponding decision sheets supplied to buyers are in Appendix B. Sellers were allowed to make small talk to put the buyers at their ease. At two points that will be identified the sellers were given a minute or two to make a sales pitch.

\section{Valuation questions}

It was explained to buyers that they would be asked to make 21 choices with each choice carrying a number. At the end of the session they would draw one of these numbers at random from a bag. The buyer's choice on this numbered question determines their payoff if, in addition, they are randomly selected as the (single) winner from the two hundred or so participants.

\footnotetext{
${ }^{8}$ The FSA were concerned with the misselling of insurance to borrowers.
} 
The first set of 11 questions was of the form:

Please tick ONE of the boxes for EACH question indicating your choice. I prefer:

My chosen item $\quad \mathrm{OR} £ \mathrm{fx}$

The value of $£ x$ goes from $£ 625$ to $£ 3,125$ in $£ 250$ increments.

These questions establish the subject's monetary equivalent, $v$, of the chosen item. $v$ is set equal to the mean of the highest monetary amount rejected and the lowest monetary amount accepted. For subjects that rejected the item in all choices, $v$ was set equal to $£ 500$ and if the item was preferred in all choices $v=£ 3,300$.

The next two sets of questions concern insurance choices. One involves income protection insurance (IPI) and the other loan payment protection insurance (LPI). Half the subjects received the income protection insurance questions first, and half the loan payment protection insurance questions first.

Income protection insurance

For the income protection case, the subject faced a risky income prospect. After answering the five questions the subjects rolled a die. If they threw anything but a six, the payoff is $v+£ 2,500$. Throwing a six means that nothing is paid. Subjects could opt for insurance at premium $p$ to protect the $v$ component of income. With insurance, the subjects received $v$ if a six is thrown and for all other numbers $v+£ 2,500-p$. The format of these questions is:

Please tick ONE of the boxes for EACH question indicating your choice.

[ ] no insurance (i.e. if you throw a '6' you get nothing and if you throw any other number you get $v+£ 2,500$ )

[ ] insurance at premium $p$ (i.e. if you throw a ' 6 ' you get $v$ and if you throw any other number you get $v+£ 2,500-p)$ 
Of course for each subject the numerical values of $v$ and $p$ were filled in. All that differs across these questions is the insurance premium, $p$. The value of $p$ was chosen to represent payout ratios of $30 \%, 40 \%, 50 \%, 70 \%, 90 \%{ }^{9}$

Had the buyers been aware that the income protection insurance questions were coming up, there would have been a strategic incentive to overstate valuations in the first set of questions since doing so provides better opportunities in the income protection insurance questions. In fact buyers were not recruited from a common organization and were unaware of the questions that would be asked.

Prior to the buyers making their insurance choices, sellers were allowed a couple of minutes to explain the virtues of insurance. The sellers were told:

"You are allowed to 'advise' the subject in your own words after you have read out the text, e.g. you might tell the subject to consider how he/she would feel if he/she had not bought insurance and had thrown a ' 6 '.'

\section{Loan payment protection insurance}

For the loan payment protection insurance questions subjects were told that they had taken out a loan to buy their chosen object. If all went well they would have enough income to repay the loan and still have £2,500 left over. However, after answering the five questions in this section, they would throw a die. If a six was thrown, it meant they had no income, the loan would not be repaid and the item would be repossessed. So in this event the subject would end up with nothing. However, insurance could be taken out to protect the loan repayment. So if insurance is chosen and a six is thrown the subject still gets to keep the item but has no income. The lender will increase the loan to pay the insurance premium, so if a six is not thrown the subject gets the object and the amount left over after repayment of the augmented loan, i.e., £2,500-p. For loan payment insurance, the format of the questions is:

\footnotetext{
${ }^{9}$ The 30\% payout ratio is towards the upper end of what actual PPI policies deliver (OFT, 2006, p. 142 and OFT 2006).
} 


\section{Please tick ONE of the boxes for EACH question indicating your choice.}

[ ] no insurance (i.e. if you throw a '6' you get nothing and if you throw any other number you get your chosen item plus the £2,500 left after repaying the loan)

[] insurance which increases the loan repayment by $p$ (i.e. if you throw a ' 6 ', you get your chosen item but no money and if you throw any other number you get your chosen item plus the £2,500-p left after repaying the loan)

Subjects again received the appropriate decision sheets with $v$ and $p$ replaced by numerical values. All that differs across the five questions is the magnitude of the premium. Sellers were again allowed to make a short "pitch" prior to the buyers making their choices.

Setting money at risk in the income protection policy equal to $v$ means that in value terms the subjects faced the same choices for both sets of questions. Hence, according to expected utility theory, subjects should make the same choices. ${ }^{10}$

Sellers were given two forms of performance pay in addition to their attendance fee. Each of the ten insurance options ticked by a subject earned the seller an extra pound. There was also a tournament element, as often employed in the insurance selling business. The seller recording the highest average number of ticked insurance options won £2,000.

\section{Information disclosure}

Two kinds of information disclosure were provided. Half the buyers were told the payout (claims) ratio for income protection insurance. ${ }^{11}$ Sellers read the following statement:

"We also provide the payout percentage for each policy. This is the percentage of the insurance company's premium income that on average it pays out to policyholders to compensate for their losses. For example, a payout percentage of $15 \%$ means that for every pound of premium income, on average the insurance company pays out 15 pence to policy holders. "

10 At least if the utility function is separable in income and the object. Hsee and Kunreuther (2000) provide evidence that people are in fact prepared to insure items they own and like for more than their monetary value. This endowment effect should also be reflected in $v$ so would not figure in our experiment.

${ }^{11}$ For loan payment protection insurance the market price of the item was not made explicit so as to make the choices easier to comprehend. Thus payout ratios could not be disclosed. 
The questions then specified the actual payout ratio.

In addition, half the buyers were informed that sellers were on performance pay. For these buyers, sellers read the following statement:

"I am required to tell you that in addition to my payment per interview I get a bonus depending on how much insurance I sell (i.e. the number of ticked insurance boxes I hand in). The salesperson who sells the most insurance will also get a prize."

The experiment thus has a 2x2x2 structure with the eight treatments summarized in Table 1. Sellers dealt with 8 buyers - one in each treatment. ${ }^{12}$

Table 1 Treatment summary

\begin{tabular}{lcccc}
\hline \hline & \multicolumn{2}{c}{ Payout ratio not revealed } & \multicolumn{2}{c}{ Payout ratio revealed } \\
& IPI first & LPI first & IPI first & LPI first \\
\cline { 2 - 5 } $\begin{array}{l}\text { Seller incentives } \\
\text { not revealed }\end{array}$ & A & B & C & D \\
$\begin{array}{l}\text { Seller incentives } \\
\text { revealed }\end{array}$ & E & F & G & H \\
\hline \hline
\end{tabular}

Once the experiment was completed, the subjects were passed to an ORC employee who asked a series of debriefing questions including whether a subject would prefer $£ 2,500$ for sure or a 50-50 lottery of $£ 8,000$ or nothing at all. The answer to this question serves as our measure of risk aversion in the following analysis. Trust is measured on a Likert scale in answer to the question "I see myself as someone who is generally trusting." (see Q2 in Table C5 in Appendix C). ${ }^{13}$ Basic demographic and economic data were collected on recruitment. ${ }^{14}$

\footnotetext{
12 Due to no-shows or overbooking of participants, a few sellers dealt with 7 or 9 buyers.

13 If the trust question were asked prior to the insurance choices it is possible that subjects would modify their behavior to live up to their self report. Asking after the choices, risks subjects giving answers that validate their behavior. However, while sellers greatly differed in their effectiveness, seller dummies do not significantly explain trust, suggesting answers were not influenced by the selling experience.

14 See Appendix C. Table C1 provides summary statistics on the general demographic, personality and lifestyle characteristics of the buyers. Table C2 shows some financial characteristics of buyers and Table
} 


\section{Results}

The distribution of the maximum payout ratios subjects are willing to buy insurance at is shown in Figure 1. Switch points are the critical payout ratios ${ }^{15}$ :

- $\quad$ 1. Don’t insure even when claim ratio 90\%.

- $\quad$ 2. Insure if claim ratio better than $70 \%$.

- $\quad 3$. Insure if claim ratio better than $50 \%$.

- 4 . Insure if claim ratio better than $40 \%$.

- $\quad$ 5. Insure if claim ratio better than $30 \%$.

- $\quad$ 6. Insure if claim ratio $30 \%$.

The modal choice is that insurance is taken whatever the payout ratios, but about $50 \%$ of subjects do not buy at a payout ratio of $30 \%$. As Figure 1 indicates, and a Wilcoxon signed-rank test confirms, there is no difference between the distribution of insurance demand to protect the chosen item (LPI) or to protect an amount of money (IPI) considered equivalent by the subjects. The correlation between the two variables is 0.46 and is highly significant. Given that the two choices were not contiguous and not framed so as to alert subjects to their similarity (subjects were not reminded of their object valuations for the LPI choice), the consistency in choices is striking. ${ }^{16}$

The most straightforward way to discover what matters for demand is to estimate a willingness to pay (WTP) for insurance function. For intermediate switch points we assign WTP as the midpoint between the highest premium for which a subject opts for insurance and the next highest premium. Less obvious is WTP for those subjects that always insure and those that never insure. For the former group we record WTP as the highest premium offered plus $£ 100$ and for the latter the lowest premium offered less $£ 50$.

C3 summarizes buyers' views related to the experiment. Table C4 provides characteristics of sellers and Table C5 shows our questions on personality traits.

15 Fewer than 5\% of question sets were filled in inconsistently in the sense of opting for insurance when the premium is high but not doing so when the premium is lower. If buyers made inconsistent choices sellers were asked to make a remark along the lines of "I notice that when the premium is higher you are more inclined to choose insurance. Is this what you intend?” If the choice was revised in the light of this prompt, this was recorded. Only 22 revised choices were made.

16 The order of LPI and IPI was not significant in willingness to pay. 
Varying these values makes little difference. Mean object WTP is $£ 1,150$ and mean money WTP is $£ 1,130$. The difference is small and not significant even at the $25 \%$ level and no variables are significant in explaining the difference. We therefore take the difference in valuations as noise and sum the two WTPs to get a more accurate measure. Running separate regressions for object and money insurance generates similar results.

\section{Figure 1}

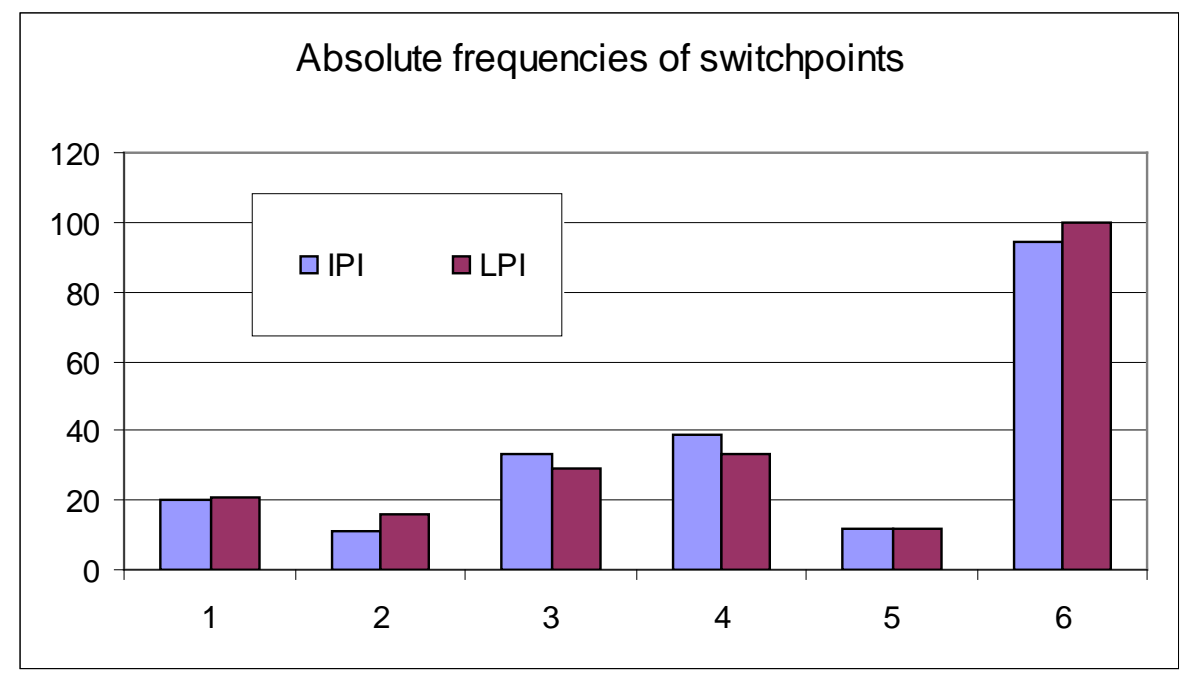

The conclusions we draw depend on all the equations we estimate, so an initial map of the findings is probably helpful:

1) Disclosure of seller incentives and payout ratios does not have significant effects on demand.

2) Demand for insurance is increasing in the extent to which buyers have a trusting nature. Magnitudes are large (the most trusting are willing to pay premiums 50\% higher than the least trusting) and trust effects are highly significant.

3) Trust is not significant in explaining risk preferences.

4) Trusting subjects are more confident their decisions are correct and feel less sales pressure. 
5) Trust is significant in explaining the field choice whether subjects purchased mortgage protection insurance (outside the experiment).

6) Sellers differ considerably in their effectiveness with the more extravert the most effective.

\section{Information disclosure}

Reminding buyers that sellers are incentivized to persuade people to buy insurance might be expected to lower demand. In OFT (2006, p. 139) it was speculated that pressurized selling may result from lenders' bonus schemes although it proved impossible to verify the existence of such schemes. Evidence is available on the Daily Mail Thisismoney site. Staff at NatWest and Royal Bank of Scotland earn three times the number of bonus points for selling a loan with payment protection insurance (PPI) than for selling the loan on its own. ${ }^{17,18}$ The reason for such bonuses is no surprise when it is realized that of the £5.4bn received in PPI premiums, some £4bn may be profits. ${ }^{19}$ Were customers aware of this, they might treat the sales pitch more skeptically and be less inclined to buy PPI or MPI. Revealing this information in the form of a low payout ratio may also be expected to depress demand for PPI, both because it indicates the policies are in some sense poor value for money and due to resentment at the exploitation. The experiment looks into these issues.

Every seller had to disclose to some of their subjects, selected at random, the payout ratios or seller incentives or both. Given an equal number with payout ratios (seller incentives) disclosed and not disclosed, buyer and seller characteristics that may affect insurance choice should be equally distributed across the disclosure and non-disclosure groups. In Table 2, equation 1 is for WTP with dummy variables to capture seller effects.

\footnotetext{
17 http://www.thisismoney.co.uk/campaigns/article.html?in_article_id=412313\&in_page_id=163

18 Looking to what is received by firms rather than individual sellers, median average commission rates for single premium policies vary from $50 \%$ for first charge mortgages to $66 \%$ for those selling unsecured loans and motor finance PPI. Median average commission rates for regular premium PPI policies varied from $35 \%$ for first charge mortgages to $70 \%$ for retail credit (FSA 2007).

${ }^{19}$ http://www.thisismoney.co.uk/campaigns/article.html?in_article_id=412482\&in_page_id=163
} 
As equation 1 shows, neither kind of disclosure has significant effects on insurance demand. $^{20}$

One possibility is that buyers interpret disclosure as honesty on the part of the seller so if anything it enhances credibility. It is true that the statement the sellers must read says they are "required" to make the disclosure but this may not be picked up by buyers. More generally, sellers may be able to neutralize the effects of disclosure, for example, by reading the statement with a laugh as if to say "this is a formality that makes no difference to our relationship".

\section{Buyer characteristics}

Equation 1 in Table 2 shows that buyer trust is highly significant. ${ }^{21}$ The coefficient implies that the most trusting individuals are prepared to pay a premium over 50\% higher than the least trusting. Other variables have the expected sign. Value at risk has the positive sign implied by standard theory and is extremely significant. Income has a significant negative effect on WTP, consistent with the usual finding of decreasing absolute risk aversion. Risk aversion, as measured by the lottery choice question does matter for insurance purchase and enters with the right sign. WTP is significantly lower for the first two sessions a seller conducts (first) and the last two (last). Sellers apparently perfect their selling technique during the day long session - at least until exhaustion decreases their performance. Age and gender were not significant and were dropped from the equation.

\footnotetext{
20 Lacko and Pappalardo (2004) find a similar result.

${ }^{21}$ Buyer trust is not significant in explaining $v$, willingness to pay for the item, which was measured prior to encountering the insurance seller. This again indicates that trust matters in the insurance decision only because of the influence of the sellers.
} 
Table 2

\begin{tabular}{|c|c|c|c|c|c|c|c|}
\hline & (1) & (2) & (3) & (4) & (5) & (6) & (7) \\
\hline Dependent Variable & WTP & $\begin{array}{c}\text { Risk } \\
\text { Aversion }\end{array}$ & Pressure & $\begin{array}{l}\text { Con- } \\
\text { fidence }\end{array}$ & $\begin{array}{l}\text { Insured } \\
\text { at all } \\
\text { Payout } \\
\text { Ratios }\end{array}$ & WTP & MPI \\
\hline Buyer Trust & $\begin{array}{l}227 * * * \\
(4.10)\end{array}$ & $\begin{array}{c}-0.02 \\
(-0.04)\end{array}$ & $\begin{array}{l}-.35 * * * \\
(-4.17)\end{array}$ & $\begin{array}{l}0.28 * * \\
(2.00)\end{array}$ & $\begin{array}{l}0.06 * * \\
(2.55)\end{array}$ & $\begin{array}{l}218^{* * *} \\
(3.55)\end{array}$ & $\begin{array}{l}0.08 * * \\
(2.01)\end{array}$ \\
\hline Seller Performance & & & $\begin{array}{c}1.36^{* * *} \\
(4.27)\end{array}$ & & $\begin{array}{c}0.72^{* * *} \\
(5.37)\end{array}$ & & \\
\hline Seller Extraversion & & & & & & $\begin{array}{l}80.1^{*} \\
(1.77)\end{array}$ & \\
\hline Value at Risk ( $v)$ & $\begin{array}{c}1020 * * * \\
(11.70)\end{array}$ & & & & $\begin{array}{l}-0.06^{*} \\
(-2.00)\end{array}$ & $\begin{array}{c}1026^{* * *} \\
(15.80)\end{array}$ & \\
\hline Income & $\begin{array}{l}-9.4 * * \\
(-2.10)\end{array}$ & $\begin{array}{l}.0001 \\
0.04\end{array}$ & & $\begin{array}{l}0.006 \\
(0.55)\end{array}$ & $\begin{array}{l}-0.003 \\
(-1.45)\end{array}$ & $\begin{array}{l}-8.66 * * \\
(-2.28)\end{array}$ & $\begin{array}{l}-0.005 \\
(-1.27)\end{array}$ \\
\hline Risk Aversion & $\begin{array}{l}417^{* *} \\
(2.30)\end{array}$ & & & $\begin{array}{l}0.78^{*} \\
(1.71)\end{array}$ & $\begin{array}{c}0.27 * * * \\
(3.95)\end{array}$ & $\begin{array}{c}244 \\
(1.60)\end{array}$ & $\begin{array}{l}-0.056 \\
(-0.44)\end{array}$ \\
\hline First & $\begin{array}{c}-386 * * \\
(2.40)\end{array}$ & $\begin{array}{l}0.14^{*} \\
(1.92)\end{array}$ & & $\begin{array}{c}0.04 \\
(0.10)\end{array}$ & $\begin{array}{c}-0.11 \\
(-1.11)\end{array}$ & $\begin{array}{l}-372 * * \\
(-2.14)\end{array}$ & \\
\hline Last & $\begin{array}{l}-314 * * \\
(-2.10)\end{array}$ & $\begin{array}{c}0.03 \\
(0.46)\end{array}$ & & $\begin{array}{c}0.21 \\
(0.56)\end{array}$ & $\begin{array}{l}-0.19 * \\
(-1.88)\end{array}$ & $\begin{array}{l}-286 * * \\
(-2.37)\end{array}$ & \\
\hline $\begin{array}{l}\text { Seller Incentives } \\
\text { Revealed }\end{array}$ & $\begin{array}{c}5.5 \\
(-0.04)\end{array}$ & & & $\begin{array}{c}-0.21 \\
(-0.64)\end{array}$ & & & \\
\hline $\begin{array}{l}\text { Payout Ratio } \\
\text { Revealed }\end{array}$ & $\begin{array}{c}35 \\
(0.28)\end{array}$ & & & $\begin{array}{c}-0.5 \\
(1.57)\end{array}$ & & & \\
\hline Worry & & & & & & & $\begin{array}{c}0.02 \\
(1.23)\end{array}$ \\
\hline Male & & $\begin{array}{l}-0.11^{*} \\
(-1.86)\end{array}$ & & & & & \\
\hline Married & & & & & & & $\begin{array}{l}0.25^{* *} \\
(2.29)\end{array}$ \\
\hline Age & & $\begin{array}{c}0.003^{* *} \\
(2.18)\end{array}$ & & & & & $\begin{array}{c}0.04 \\
(0.82)\end{array}$ \\
\hline \multirow[t]{2}{*}{ Age Squared } & & & & & & & $\begin{array}{r}-0.0006 \\
(-1.07) \\
\end{array}$ \\
\hline & $\begin{array}{l}n=186 \\
R^{2}=0.6\end{array}$ & $\begin{array}{c}n=192 \\
R^{2}=0.24\end{array}$ & $\begin{array}{c}n=207 \\
R^{2}=0.11\end{array}$ & $\begin{array}{c}n=191 \\
R^{2}=0.23\end{array}$ & $\begin{array}{c}n=186 \\
R^{2}=0.24\end{array}$ & $\begin{array}{l}n=186 \\
R^{2}=0.5\end{array}$ & $n=88$ \\
\hline
\end{tabular}

Equations 1-4 include seller dummies. Equations 5 and 6 have standard errors clustered by sellers. $t$-values in brackets. ***means significant at the $1 \%$ level, ** 5\%, and * $10 \%$. "Seller Extraversion" is measured by combining answers to Q1 and (with reversed sign) answers to Q6 in Table C5 (Rammstedt and John 2007). 
The most obvious objection to the claim that equation (1) provides evidence of the importance of trust is that the variable is proxying for risk aversion. Equation 2 suggests this is not so. Trust is not significant in explaining risk aversion though gender and age do have the conventional signs. ${ }^{22}$ It is somewhat surprising that those sold insurance at the start of the day are more risk averse. However, psychologists have found that moods vary through the day. For example, people are least optimistic in the late afternoon (Thayer 1987). So it is not impossible that the risk aversion effect is real.

If buyer trust is a measure of the extent to which buyers do not question the advice that they receive from sellers then more trusting types should feel less pressured by sellers. Similarly, if the trusting are less inclined to question what they are told, they will be more confident in their decisions. Equations 3 and 4 show that both implications apply.

A possible objection to the claim that trust determines WTP is that the selling experience determines the answer to the subsequently administered trust question. People who are swayed by the seller justify themselves by reporting they are trusting. ${ }^{23}$ To address this issue we regressed individual trust on the seller performance variable defined in the next section and found that it was not significant indicating that trust is not endogenous.

As remarked in the Introduction, mortgage protection insurance in the UK has typically been sold face-to-face after a mortgage deal is agreed. It has low payout ratios and many exclusions. Trust might therefore be thought to play a part in its purchase. Equation (7) regresses a dummy for holding MPI outside the experiment on trust and other variables. The subjects are restricted to those with mortgages in full time employment (the most important role of MPI is to cover spells of unemployment). MPI is a product that has only come to prominence in recent years as banks have recognised its profitability. Unfortunately, we do not have data on when the mortgage was taken out but this may be approximated by the age of the subjects. Given the long-term nature of the cover and its

\footnotetext{
22 These variables are included to help validate the risk preference measure but were not significant in the WTP equations.

${ }^{23}$ Of course, had the trust question been asked be prior to the insurance questions the choices might have been modified to justify the trusting claim.
} 
magnitude it might be that subjects with a tendency to worry might be attracted to MPI. According to equation (7) trust is indeed important in this setting. ${ }^{24}$

So far the emphasis has been on buyer characteristics. As not all sellers will be equally trustworthy, or skilled at presenting themselves as such, and if trust makes buyers more receptive to seller claims, it should matter for WTP whom a buyer is matched with.

\section{Influence of sellers}

F-tests were performed on equation 1 to check whether the seller effects are significant.

The F statistic equals 2.46 with significance level 0.0005 , indicating that seller effects are indeed very important in explaining WTP. The seller effects are not only statistically significant, they are also large. The three worst sellers achieved WTP 34\% below average and the three best $43 \%$ above (both measures controlling for buyer characteristics).

Equation 5 provides an alternative perspective on seller effects. The dependent variable is a dummy equal to one if the individual buys both types of insurance at the lowest (30\%) payout rate. The seller performance variable indicates, for each subject, the seller's success with other subjects. That is, for each subject, seller performance equals the fraction of the seller's other subjects who bought insurance at all payout ratios. If insurance choices only depend on intrinsic risk preferences, others’ decisions regarding insurance purchase from a particular seller should not affect a subject's insurance choice. However, it is evident from equation 5 that a seller's success in selling to other subjects is a highly significant predictor of the chance that a subject buys insurance at $30 \%$ payout ratio. This again provides evidence that sellers differ in their ability to persuade buyers to take out insurance policies. Risk aversion is considerably more significant than in the first equation. This may be because the binary measure captures the most risk averse and in this regression the dependent variable is also a binary division for the most willing to insure. Buyer trust remains significant though somewhat less so. Equation 5 has the same message as equation 1. Rather than basing their insurance purchase decision on the

\footnotetext{
${ }^{24}$ In contrast trust was not significant in explaining whether subjects purchased travel insurance (some $50 \%$ of the sample did). Travel insurance is not normally sold face-to-face so trust would not be expected to be so important.
} 
objective characteristics of policies, buyers appear to be highly susceptible to seller influence.

At first sight, seller effects will be greater for more trusting subjects if trust really is a measure of credulity. This does not follow, so testing for interaction effects is not appropriate. Suppose $W=f(M(S, T), X)$ where $W$ is WTP, $M$ is message effectiveness, $S$ is an index of seller effectiveness, $T$ is buyer trust and $X$ a vector of other relevant effects. Then $W_{S}=f_{M} M_{S}$ and $W_{S T}=f_{M M} M_{T} M_{S}+f_{M} M_{S T}$. The natural assumptions are that $f_{M M}<0, M_{T}$, $M_{S}>0, f_{M}>0$, and $M_{S T}$ is of ambiguous sign. So if more effective sellers are able to enhance message effectiveness by the same magnitude whatever the degree of buyer trust $\left(M_{S T}=0\right)$ then the greater is buyer trust, the less difference is made by a good seller. A necessary but not sufficient condition to reverse this conclusion is that good sellers are more effective in enhancing the message when the buyer is trusting.

Though it seems clear that there are seller effects, equations 1, 2, and 5 do not identify what it is about sellers that makes them successful. Equation 6 shows that more extravert sellers generate higher WTP. It is plausible that extraverts are best able to bond in a short time and project the right image of trustworthiness.

\section{Discussion: Trust and Openness to Persuasion}

Whereas a burgeoning empirical literature finds that trust matters for aggregate economic performance (Knack and Keefer 1997, Zak and Knack 2001, Tabellini 2008, Algan and Cahuc 2010), why trust matters remains an open question. In the context of financial markets, Guiso, Sapienza and Zingales (2008), building on Guiso, Sapienza and Zingales (2004), report that generalized trust is a significant determinant of whether individuals invest in the stock market and that countries exhibiting greater average levels of trust have higher stock market participation rates. The interpretation they give is that low-trust individuals expect low returns because they believe there is an appreciable chance that "the company is just a scam, that the manager steals all the proceeds, or that the broker absconds with the money instead of investing it” (p. 2563). In their formulation, investors are indifferent to how they lose money, whether through being cheated or through bad 
luck. Since outright fraud is rare in most economies, it can only be a major discouragement to buying stocks if low-trust individuals are highly pessimistic, contrary to the general finding that optimism is the norm. Moreover, portfolio diversification effectively mitigates the risk of losing money through fraud.

An alternative view is that whereas trust concerns beliefs about the future behavior of the trustee, the reason it matters so much is down to preferences. Many people think it is worse to lose money through a scam than through an honest gamble that fails. There is experimental evidence of such "betrayal aversion" (Bohnet et al. 2008, Bohnet, Herrmann and Zeckhauser 2010). If people put high weight on not being made a fool of, trust becomes a much more powerful determinant of behavior even if the objective chance of fraud is low.

This paper is about a third, neglected, channel through which trust may operate. This involves beliefs, but not about future behavior. The claim is that in all situations people with high trust tend to believe what they are told, including hype. For example, trusting types really believed that dotcoms had created a new economy or that "Avis try harder”. Such credulity is especially likely if the message is delivered personally. ${ }^{25}$ "Blue really suits you”. "You won't find a better insurance policy than the one I am selling”. "Now is the right time to buy stocks". "Imagine the effect on your family if you would lose your job and you don’t have income protection insurance.” The information content of these messages is negligible and certainly does not concern the future behavior of the persuader. What the messages rely on is that trusting people don't need much reason to follow advice. Nor is the thought that such recommendations may be self-serving troubling. "Trusting your bank" is associated with greater stock market participation

25 In one-shot trust games in which subjects were shown photographs of their partners, Scharlemann et al. (2001) find that smiling positively affects trust among strangers. Valley, Moag and Bazerman (1998) investigate the influence of face-to-face communication in a bilateral bargaining situation with asymmetric information and find improvements in efficiency. "Face-to-face negotiations nearly always involved a significant proportion of the early bargaining time taken up in getting to know more about one another and talking about topics unrelated to the negotiation, setting a positive tone for the entire negotiation... trust was discussed explicitly. For example, a buyer tried to explain to a seller why he was having a hard time accepting at face value her (truthful) claim... 'How can I trust you?... It's all a matter of trust.' This pair went on to slowly reveal the private information held by each side.” (pp. 230-231). 
because their advice to buy shares is believed not because it measures the probability clients think the bank will abscond with the funds.

Most definitions of trust identify willingness to delegate as the key element. According to Fehr (2009), "An individual...trusts if she voluntarily places resources at the disposal of another party without any legal commitment from the latter.” (p. 238). In Rousseau et al. (1998), "Trust is a psychological state comprising the intention to accept vulnerability based upon positive expectations of the intentions or behavior of another.” (p. 395). Both definitions imply a willingness to hand control to someone who has the potential to take advantage of the trustor. It is debatable whether these formulations cover willingness to believe what others tell you even if there is no resource transfer. Visiting Sir John Soane's Museum in London based on a conversation with a stranger at an airport certainly seems to involve trust, but no resources are placed at the disposal of another. The persuadability component of trust that arises in our experiment has been neglected in the literature, but is important in many economic contexts such as advertising, professional services and so forth. ${ }^{26}$ The reason trust appears to influence aggregate economic performance (as in the literature initiated by Knack and Keefer 1997 and Zak and Knack 2001) may not just be that it facilitates transactions but because people respond to the advice of teachers, friends and governments. ${ }^{27}$

Some studies have attempted to find a link between generalized trust questions and behavior in the trust game. The motivation is that (for economists) the amount sent is a direct measure of trust, so if it is not correlated with the trust question, this challenges its interpretation in macro studies of economic performance. However, in the trust game, persuasion does not have a role to play. Our contention is that one route by which trust matters in an economy is because it implies openness to persuasion. In our setting, neither

\footnotetext{
26 Akerlof and Shiller (2009) argue that trust, in the sense investigated here, played a major role in the financial crisis. The boom was exaggerated by over-confidence. The etymology of confidence is from fido, I trust. People trusted the general hype that house prices would rise. Lewis (2010) amongst others argues that even supposedly sophisticated bankers took the judgement of ratings agencies on CDOs on trust.

27 If trust and trustworthiness evolve together then high trust economies may perform best although the most trusting in any society may be worse off because they tend to be duped. Butler, Giuliano and Guiso (2009) find evidence along these lines.
} 
reciprocation nor betrayal-aversion are relevant but generalized trust may still matter because it is associated with openness to persuasion. ${ }^{28}$

Evidence on whether generalized trust explains behavior in the trust game is mixed. Sapienza, Tolda and Zingales (2007) find that for incoming Chicago MBAs, the amount sent is mainly but not entirely explained by the sender's beliefs as to the receiver's behavior, which in turn correlate with standard survey questions about trusting others. Fehr et al. (2003) also find that for a representative sample of the German population, trust increases the amount sent, but Glaeser et al. (2000) do not obtain a significant correlation. Sapienza, Tolda, and Zingales (2007) conjecture that the reason for this is that the Glaeser et al. subjects are seasoned Harvard undergraduates, a relatively homogeneous population. These students think the receiver is probably just like them, and (falsely) extrapolate their own trustworthiness to the likely behavior of the receiver. Hence, generalized trust does not explain the amount sent, though it would if the subjects were drawn from the whole population, because then it is realized that most people are not 'just like me' so trust cannot be projected. In our experiment, buyers have little knowledge of the sellers background so the "just like me projection" is unlikely to apply so generalized trust is potentially relevant.

This paper argues that trust matters for mediated insurance purchase even when betrayal is not an issue. Guiso, Sapienza and Zingales (2008) propose that trust may matter for the purchase of insurance contracts because they are financial contracts with "delayed and uncertain repayment”. They find that those with private health insurance are more trusting, but the effect is not significant. In our experiment, insurance does not involve delay or contractual uncertainty, but trust is a highly significant determinant of demand. Sellers do not reassure that the terms will be honored in spirit or letter, but explain the

\footnotetext{
28 Guilt aversion, introduced by Charness and Dufwenberg (2005), provides a possible reason why. Buyers do not wish to disappoint the expectation of sellers. This may help explain why disclosure of sellers' commission is ineffective. So trusting behavior is motivated by the taste for guilt (or perhaps rudeness) aversion.
} 
psychological merits of being insured. ${ }^{29}$ Trust matters because it determines the extent to which the buyer takes the seller's advice at face value. ${ }^{30}$

\section{Conclusion}

The message of this paper is twofold. First, we find no evidence that disclosure of seller incentives and actual payout ratios substantially changes buyers' behavior. Second, trust seems to play a major role in face-to-face (insurance) selling since intrinsically trusting people are easily persuaded. This neglected aspect of trust is potentially important. It implies people are easily taken in by self-interested advisers such as sales people. Competition in the persuasion market may neutralize some of the resulting bias, but not all of it. Rival pitches by, say, car makers may perhaps result in a balanced final evaluation of which car to buy but the case for not having a car at all may go unstated. Appropriate intervention depends on the extent to which consumers are credulous. For example, Inderst and Ottaviani (2009) show that in markets in which sellers advise buyers, whether there should be statutory cancellation and a returns policy depends on the extent to which consumers believe cheap talk.

In our experiment, seller persuasion, not just intrinsic risk preference, is a major influence on insurance decisions. Whether an individual is insured depends on which seller they are matched with. Some sellers are particularly effective and trusting buyers are especially susceptible to seller influence. ${ }^{31}$ Given the importance of trust, it is not surprising that the disclosure of seller commissions has little effect on choice. The design of the experiment eliminates the possibility that trust matters because of uncertainty about whether parties

\footnotetext{
${ }^{29}$ If there was doubt about whether promises would be kept it is not obvious why they would specifically affect the insurance option and not the alternative experimental choices.

30 Schotter (2003) observes that laboratory subjects exhibit a general tendency to follow advice even when advisers are naïve in the sense that they are hardly more expert in the task at hand than the advisees. The influence of advisees' trust is not measured in these experiments.

31 This intuition is in line with recent findings on the biological basis of trust since human mechanisms for social bonding and the inclination to trust seem to share common biochemical foundations. Kosfeld et al. (2005) find that the neuropeptide oxytocin increases the amount sent by first movers in the trust game. Guastella, Mitchell, and Mathews (2008) show that oxytocin-administered humans are more likely to recollect happy human faces compared with angry and neutral ones. This indicates that oxytocin enhances the encoding of positive social approach, intimacy, and bonding by strengthening encoding of positive social information over social information that is either neutral or negative.
} 
will fulfill future obligations. Instead, the key feature is willingness to accept advice at face value. This feature allows trust to have more pervasive effects than do existing interpretations.

Relative to the typical mortgage protection insurance purchase environment, where the persuader has monopoly access to the buyer and the interaction is an extended one, buyers in the experiment were less exposed to seller pressure. Moreover, the insurance industry has every incentive to recruit the most effective sellers. It therefore seems likely that our results would be at least as strong for actual (face-to-face) sales. ${ }^{32}$ Also, the policies offered in the experiment were considerably simpler than real MPI and PPI products. This simplicity seems likely to curtail the ability of sellers to sway choices; in more complicated real insurance settings seller influence is probably even more important. ${ }^{33}$ The experiment therefore appears relevant in identifying the determinants of demand for policies available in the market. This is confirmed by the finding that subjects with a more trusting disposition are more likely to have bought MPI outside the experiment.

Economies exhibiting high levels of trust tend to be more prosperous. The usual explanation is that trust and trustworthiness co-evolve to provide a social remedy to the problem of incomplete contracts. The results of our experiment suggest another mechanism. Trusting people do what they are told. Could it be that some level of persuadability is good for economic growth?

\footnotetext{
32 Some 55\% of PPI purchases are made in face-to-face sales (FSA 2007).

33 In a survey of PPI purchase it was reported "Respondents showed virtually no engagement with the product and relied on whatever they were told by the sales adviser” (FSA 2007)
} 


\section{References}

Akerlof, George and Robert Shiller (2009) Animal Spirits: How Human Psychology Drives the Economy, and Why It Matters for Global Capitalism Princeton University Press.

Algan, Yann and Pierre Cahuc (2010) Inherited trust and growth. forthcoming in: American Economic Review.

Ariely, Dan, George Loewenstein, and Drazen Prelec (2003) "Coherent arbitrariness": Stable demand curves without stable preferences. Quarterly Journal of Economics 118(1), 73-105.

Berg, Joyce, John Dickhaut, and Kevin McCabe (1995) Trust, reciprocity and social history. Games and Economic Behavior 10, 122-142.

Bertrand, Marianne and Adair Morse (2009) Information disclosure, cognitive biases and payday borrowing. MFI Working Paper No. 2009-007 University of Chicago, Booth School of Business.

Bertrand, Marianne, Dean Karlan, Sendhil Mullainathan, Eldar Shafir, and Jonathan Zinman (2010) What's advertising content worth? A field experiment in the consumer credit market. Quarterly Journal of Economics 125(1), 263-305.

Bohnet, Iris, Fiona Greig, Benedikt Herrmann, and Richard Zeckhauser (2008) Betrayal aversion: Evidence from Brazil, China, Oman, Switzerland, Turkey, and the United States. American Economic Review 98(1), 294-310.

Bohnet, Iris, Benedikt Hermann, and Richard J. Zeckhauser (2010) Trust and the Reference Point for Trustworthiness in Gulf and Western Countries. Quarterly Journal of Economics 125(2), 811-828.

Butler, Jeffrey, Poala Giuliano and Luigi Guiso (2009) The right amount of trust. NBER Working Paper 15344.

Cain, Daylain, George Loewenstein, and Don Moore (2005) The dirt on coming clean: Perverse effects of disclosing conflicts of interest. Journal of Legal Studies 34, 1-25.

Charness, Gary and Martin Dufwenberg (2006) Promises and partnership. Econometrica 74(6), 1579-1601.

Della Vigna, Stefano and Matthew Gentzkow (2010) Persuasion: Empirical evidence. Annual Review of Economics 2, 643-669.

De Steno, David, Richard E. Petty, Derek D. Rucker, Duane T. Wegener, and Julia Braverman (2004) Discrete emotions and persuasion: The role of emotion induced expectancies. Journal of Personality and Social Psychology 86, 43-56.

Eckel, Catherine and Rick K. Wilson (2004) Is trust a risky decision? Journal of Economic Behavior \& Organization 55, 447-465.

Eyster, Eric and Matthew Rabin (2005) Cursed equilibrium. Econometrica 73, 16231672. 
Fehr, Ernst, Urs Fischbacher, Bernhard von Rosenbladt, Jürgen Schupp, and Gert G. Wagner (2003) A nation-wide laboratory: Examining trust and trustworthiness by integration behavioral experiments into representative surveys. CESifo Working Paper 866.

Fehr, Ernst (2009) On the economics and biology of trust. Journal of the European Economic Association 7(2-3), 235-266.

Financial Services Authority (2007) ICOB Review Interim Report: Consumer Experiences and Outcomes in General Insurance Markets.

Georges, Laurent and Paolo Guenzi (2009) Salesperson's trust in the context of the financial services. Discussion paper, Bocconi University.

Gibbons, Robert, Frank J. Landry, Denise L. Blouch, David L. Jones, Frederick K. Williams, Catherine R. Lucey, and Kurt Kroenke (1998) A comparison of physicians' and patients' attitudes toward pharmaceutical industry gifts. Journal of General Internal Medicine 13(3), 151-54.

Gneezy, Uri (2005) Deception: The role of consequences. American Economic Review 95(1), 384-394.

Glaeser, Edward L., David Laibson, Jose D, Scheinkman, and Christine L. Soutter (2000) Measuring trust. Quarterly Journal of Economics 65(August), 811-846.

Guastella, Adam J., Philip B. Mitchell, and Frosso Mathews (2008) Oxytocin enhances the encoding of positive social memories in humans. Biological Psychiatry 64, 256-258.

Guiso, Luigi, Paola Sapienza, and Luigi Zingales (2004) The role of social capital in financial development. American Economic Review 94, 526-556.

Guiso, Luigi, Paola Sapienza, and Luigi Zingales (2008) Trusting the stock market. Journal of Finance 63, 2557-2600.

Hsee, Christopher K. and Howard C. Kunreuther (2000) The affection effect in insurance decisions. Journal of Risk and Uncertainty 20(2), 149-159.

Inderst, Roman and Marco Ottaviani (2009) Sales talk, cancellation terms, and the role of consumer protection. Discussion paper, University of Frankfurt (IMFS).

Knack, Stephen and Philip Keefer (1997) Does social capital have an economic payoff? A cross-country investigation. Quarterly Journal of Economics 112(4), 1252-88.

Kosfeld, Michael, Markus Heinrichs, Paul J. Zak, Urs Fischbacher, and Ernst Fehr (2005) Oxytocin increases trust in humans. Nature 435, 673-676.

Koch, Christopher and Carsten Schmidt (2010) Disclosing conflicts of interest - Do experience and reputation matter? Accounting, Organizations and Society 35, 95-107.

Kruschke, John K. and Mark K. Johansen (1999) A model of probabilistic category learning. Journal of Experimental Psychology: Learning, Memory, and Cognition 25, 1083-1119.

Lacko, James and Janis K. Pappalardo (2004) The effect of mortgage broker compensation disclosures on consumers and competition: A controlled experiment. Federal Trade Commission Bureau of Economics Staff Report. 
Lewis, Michael (2010) The Big Short: Inside the Doomsday Machine W.W. Norton Malmendier, Ulrike and Devin Shanthikumar (2007) Are small investors naive about incentives? Journal of Financial Economics 85(2), 457-489.

Mercer, Molly (2005) The fleeting effects of disclosure forthcomingness on management's reporting credibility. Accounting Review 80 (2), 723-744.

Milgram, Stanley (1963) Behavioral study of obedience. Journal of Abnormal and Social Psychology 67(4), 371-378.

Milgrom, Paul (2008) What the seller won't tell you: Persuasion and disclosure in markets. Journal of Economic Perspectives 22(2), Spring, 115-131.

Mixon, Don (1971) Further conditions of obedience and disobedience to authority. Doctoral dissertation. University of Nevada.

Mixon, Don (1972) Instead of deception. Journal for the Theory of Social Behavior 2(2), 145-178.

Mullainathan, Sendhil, Joshua Schwartzstein, and Andrei Shleifer (2008) Coarse thinking and persuasion. Quarterly Journal of Economics 123(2), 577-619.

OFT (2006) Research into payment protection insurance in the UK (non confidential version) Annex A of Payment protection insurance "Report on the market study and proposed decision to make a market investigation reference" http://www.oft.gov.uk/shared_oft/reports/financial_products/oft869annexea.pdf

Rammstedt, Beatrice and Oliver P. John (2007) Measuring personality in one minute or less: A 10-item short version of the Big Five inventory in English and German. Journal of Research in Personality 41, 203-212.

Rousseau, Denise M., Sim B. Sitkin, Ronald S. Burt, and Colin Camerer (1998) Not so different after all: A cross-discipline view of trust. Academy of Management Review 23(3), 393-404.

Sapienza, Paola, Anna Tolda, and Luigi Zingales (2007) Understanding trust. NBER Working Paper 13387.

Scharlemann, Jörn P.W., Catherine C. Eckel, Alex Kacelnik, and Rick K. Wilson (2001) The value of a smile: Game theory with human face. Journal of Economic Psychology 22, 617-640.

Schotter, Andrew (2003) Decision making with naïve advice. American Economic Review 93(2), 196-201.

Swan, John E., Michael R. Bowers, and Lynne D. Richardson (1998) Customer trust in the salesperson: An integrative review and meta-analysis of empirical literature. Journal of Business Research 44, 93-107.

Tabellini, Guido (2008) Institutions and culture: Presidential address. Journal of the European Economic Association 6(2-3), 255-294.

Thayer, Robert (1987) Problem perception, optimism, and related states as a function of time of day (diurnal rhythm) and moderate exercise: Two arousal systems in interaction. Motivation and Emotion 11, 19-36. 
Valley, Kathleen L., Joseph Moag, and Max H. Bazerman (1998). 'A matter of trust': Effects of communication on the efficiency and distribution of outcomes. Journal of Economic Behavior \& Organization 34, 211-238.

Zak, Paul J. and Stephen Knack (2001) Trust and growth. Economic Journal 111(470), 295-321 
Appendix A

Script for Treatment $\mathrm{H}$

\title{
Instruction sheets $\mathbf{H}$
}

\author{
for sellers
}


Ask the participant which item he/she has chosen. Make sure that all items are filled in on the cover page of the decision sheets.

Read the following instructions aloud to the participant...

Thank you for agreeing to participate in this experiment on financial decision making being run for the Financial Services Authority by the London School of Economics and implemented by ORC.

In addition to your participation fee of $£ 25$, which is yours for sure, you could win a substantial amount of cash and/or your selected item.

The procedure is that you will be asked to answer twenty one numbered questions involving choices between money amounts and/or your selected prize item. In this bag there are 21 numbers (from 1 to 21), one for each question. At the end of the session I will ask you to draw one number at random. The number on it identifies the question that will determine your outcome if you are the person selected as the overall winner. What you will get if you are the winner is the option you selected in that question.

The overall winner will be selected at random from about two hundred participants once the experiment is completed. If you are the winner you will be notified by mid-October.

When answering each of the 21 questions, you should therefore think carefully about your answers since one of them will determine what you obtain if you are the overall winner.

The first set of questions involves choosing between your selected prize item and amounts of money. In successive questions the cash alternative is increased so you have to decide when the amount of money is high enough to become the preferred option. 


\section{SHEET 1:}

\section{HAND SHEET 1 TO BUYER}

\section{Ask the participant to look at decision sheet 1.}

Go through all the questions with the participant, explicitly mentioning the actually chosen item in each question, e.g., if they have chosen the motorbike, refer specifically to it rather than the 'item'

\section{Let the participant make his/her choice for each question.}

Either after all choices have been made, or as they are making them, you should make sure that their choices are logically consistent, i.e. they have one of the following three patterns:

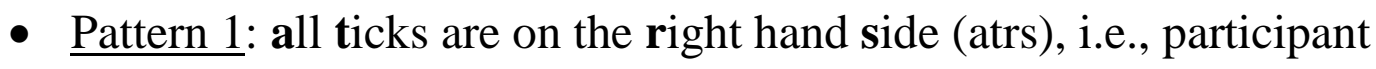
chooses cash in all questions

- Pattern 2: ticks have one "switchpoint”, i.e., they start on the left hand side with question 1 and continue till, for example, question 4 . Then there is a switch to the right hand side at question 5 and all following ticks are on the right hand side. Such a pattern will be denoted by "sp4-5". So, if the switch from the left column to the right column occurs between question 2 and 3, we call this “sp2-3”, etc.

- Pattern 3: all ticks are on the left hand side (atls), i.e., participant chooses item in all questions

If the ticks do not follow one of these patterns explain the inconsistency to the participant and ask him/her to revise until the pattern is logically consistent.

If the subject requires prompting for decisions to be consistent please tick the "r"-box - for revised - at the bottom of decision sheet 1. 


\section{SHEET 2:}

Now you have to provide the participant with the right instructions for decision sheet 2. There are different versions of instructions, i.e., one for each "switchpoint" from decision sheet 1 . The acronyms will help you to find the right ones. Examples...

- If on sheet 1 they have ticked all of the cash amounts then for sheet 2 they should be taken to the one labelled 'atrs' (i.e. 'all ticks on the right hand side')

- If on sheet 1 they have ticked all of their prize item (e.g. the motorbike, Rolex watch, cruise etc.) then for sheet 2 they should be taken to the one labelled 'atls' (i.e. 'all ticks on the left hand side')

- If the point at which they switch from the item to the cash amount or vice versa is after trade-off 3 for example, they should be taken to the sheet 2 labelled ‘sp3-4’ (switch point between q’s 3 and 4)

- ...see below for examples...

\section{Sheet 1}

Please tick ONE of the boxes for EACH question indicating your choice.

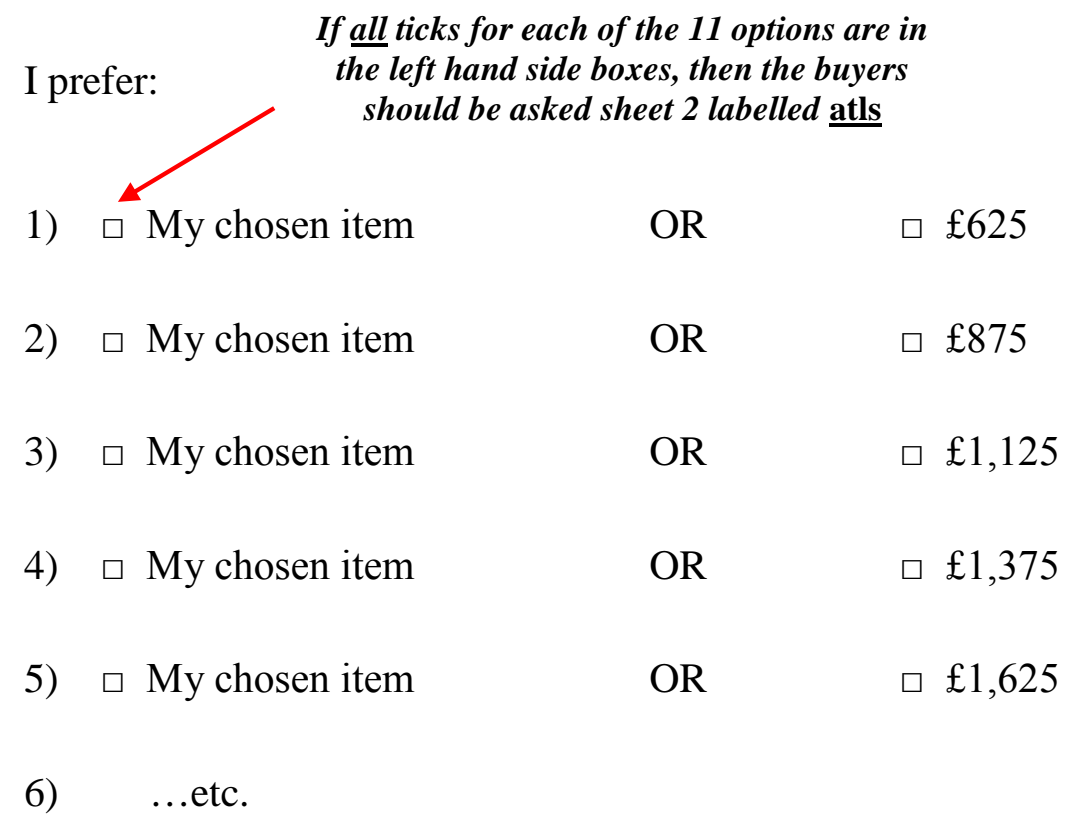




\section{Sheet 1}

Please tick ONE of the boxes for EACH question indicating your choice.

I prefer:

1) $\square$ My chosen item

OR

If all ticks for each of the 11 options are in the right hand side boxes, then the buyers should be asked sheet 2 labelled atrs

2) $\square$ My chosen item

OR

$£ 625$

3) $\square$ My chosen item

OR

$£ 1,125$

4) $\square$ My chosen item

OR

$£ 1,375$

5) $\square$ My chosen item

OR

$£ 1,625$

6) $\quad$...etc.

\section{Sheet 1}

Please tick ONE of the boxes for EACH question indicating your choice.

I prefer:

1) $\square$ My chosen item

OR

$\square £ 625$

2) $\square$ My chosen item

OR

$\square £ 875$

If the item is chosen for say the first 2 trade offs (i.e. on the left hand side), but they continue to

OR

$\square £ 1,125$ right hand side from then on,

3) $\square$ My chosen item

OR

$\square £ 1,375$

5) $\square$ My chosen item

OR

$\square £ 1,625$

6) $\quad$...etc. 
After deriving the correct sheet 2 to take the buyer through read the instruction which matches their decision pattern from sheet 1 i.e. were they arts, atls, sp1-2, sp2-3 etc. (see next pages). 


\section{atrs: ('all ticks on the right hand side')}

$>$ Ensure you have the correct decision sheet 2 for the buyer (i.e. the arts, atls, sp1-2 etc. as derived from the sheet 1 answers) and make sure you encourage the subject to read the questions and smallprint carefully.

Now you are facing a decision situation in which your chosen item does not figure.

Your income depends on your throw of the die. If you roll a '6' your income will be zero.

Otherwise your income is $£ 3,000$.

You can now buy an income protection policy. If you buy an income protection policy and you throw

- a '6' the policy pays you $£ 500$ to compensate for the loss of income.

- any other number your income is $£ 3,000$ minus the insurance premium.

In successive questions the premium is increased so you have to decide when it is sufficiently high that not taking insurance becomes the preferred option.

We also provide the payout percentage for each policy. This is the percentage of the insurance company's premium income that on average it pays out to policyholders to compensate for their losses.

For example, a payout percentage of $15 \%$ means that for every pound of premium income, on average the insurance company pays out 15 pence to policy holders.

I am required to tell you that in addition to my payment per interview I get a bonus depending on how much insurance I sell (i.e. the number of ticked insurance boxes I hand in). The salesperson who sells the most insurance will also get a prize.

$>$ You are allowed to 'advise' the subject in your own words after you have red out the text, e.g., you might tell the subject to consider how he/she would feel if he/she had not bought insurance and had thrown a ' 6 '.

$>$ Subjects must fill out the sheet themselves

$>$ Whilst the buyer is filling out their sheet you are now only allowed to talk if the subject asks a question or makes inconsistent choices, e.g., switch between insurance and no insurance twice.

$>$ If the subject requires prompting for decisions to be consistent please tick the " $r$ "-box for revised - at the bottom of decision sheet 2.

$>\quad$ When all choices are made, ask the participant to throw the die. Enter the thrown number in the box at the bottom of the decision sheet. 


\section{Sp1-2}

$>$ Ensure you have the correct decision sheet 2 for the buyer (i.e. the arts, atls, sp1-2 etc. as derived from the sheet 1 answers) and make sure you encourage the subject to read the questions and smallprint carefully.

Now you are facing a decision situation in which your chosen item does not figure.

Your income depends on your throw of the die. If you roll a '6' your income will be zero.

Otherwise your income is $£ 3,250$.

You can now buy an income protection policy. If you buy an income protection policy and you throw

- a '6' the policy pays you $£ 750$ to compensate for the loss of income.

- any other number your income is $£ 3,250$ minus the insurance premium.

In successive questions the premium is increased so you have to decide when it is sufficiently high that not taking insurance becomes the preferred option.

We also provide the payout percentage for each policy. This is the percentage of the insurance company's premium income that on average it pays out to policyholders to compensate for their losses.

For example, a payout percentage of $15 \%$ means that for every pound of premium income, on average the insurance company pays out 15 pence to policy holders.

I am required to tell you that in addition to my payment per interview I get a bonus depending on how much insurance I sell (i.e. the number of ticked insurance boxes I hand in). The salesperson who sells the most insurance will also get a prize.

$>$ You are allowed to 'advise' the subject in your own words after you have red out the text, e.g., you might tell the subject to consider how he/she would feel if he/she had not bought insurance and had thrown a ' 6 '.

$>$ Subjects must fill out the sheet themselves

$>$ Whilst the buyer is filling out their sheet you are now only allowed to talk if the subject asks a question or makes inconsistent choices, e.g., switch between insurance and no insurance twice.

$>$ If the subject requires prompting for decisions to be consistent please tick the " $r$ "-box for revised - at the bottom of decision sheet 2.

$>$ When all choices are made, ask the participant to throw the die. Enter the thrown number in the box at the bottom of the decision sheet. 


\section{Sp2-3}

Ensure you have the correct decision sheet 2 for the buyer (i.e. the arts, atls, sp1-2 etc. as derived from the sheet 1 answers) and make sure you encourage the subject to read the questions and smallprint carefully.

HAND SHEET 2 TO BUYER \& READ OUT FOLLOWING TEXT TO THEM

Now you are facing a decision situation in which your chosen item does not figure.

Your income depends on your throw of the die. If you roll a '6' your income will be zero.

Otherwise your income is $£ 3,500$.

You can now buy an income protection policy. If you buy an income protection policy and you throw

- a ' 6 ' the policy pays you $£ 1,000$ to compensate for the loss of income.

- any other number your income is $£ 3,500$ minus the insurance premium.

In successive questions the premium is increased so you have to decide when it is sufficiently high that not taking insurance becomes the preferred option.

We also provide the payout percentage for each policy. This is the percentage of the insurance company's premium income that on average it pays out to policyholders to compensate for their losses.

For example, a payout percentage of $15 \%$ means that for every pound of premium income, on average the insurance company pays out 15 pence to policy holders.

I am required to tell you that in addition to my payment per interview I get a bonus depending on how much insurance I sell (i.e. the number of ticked insurance boxes I hand in). The salesperson who sells the most insurance will also get a prize.

> You are allowed to 'advise' the subject in your own words after you have red out the text, e.g., you might tell the subject to consider how he/she would feel if he/she had not bought insurance and had thrown a ' 6 '.

$>$ Subjects must fill out the sheet themselves

$>$ Whilst the buyer is filling out their sheet you are now only allowed to talk if the subject asks a question or makes inconsistent choices, e.g., switch between insurance and no insurance twice.

$>$ If the subject requires prompting for decisions to be consistent please tick the " $r$ "-box for revised - at the bottom of decision sheet 2.

$>$ When all choices are made, ask the participant to throw the die. Enter the thrown number in the box at the bottom of the decision sheet. 
$>$ Ensure you have the correct decision sheet 2 for the buyer (i.e. the arts, atls, sp1-2 etc. as derived from the sheet 1 answers) and make sure you encourage the subject to read the questions and smallprint carefully.

Now you are facing a decision situation in which your chosen item does not figure.

Your income depends on your throw of the die. If you roll a ' 6 ' your income will be zero.

Otherwise your income is $£ 3,750$.

You can now buy an income protection policy. If you buy an income protection policy and you throw

- a ' 6 ' the policy pays you $£ 1,250$ to compensate for the loss of income.

- any other number your income is $£ 3,750$ minus the insurance premium.

In successive questions the premium is increased so you have to decide when it is sufficiently high that not taking insurance becomes the preferred option.

We also provide the payout percentage for each policy. This is the percentage of the insurance company's premium income that on average it pays out to policyholders to compensate for their losses.

For example, a payout percentage of $15 \%$ means that for every pound of premium income, on average the insurance company pays out 15 pence to policy holders.

I am required to tell you that in addition to my payment per interview I get a bonus depending on how much insurance I sell (i.e. the number of ticked insurance boxes I hand in). The salesperson who sells the most insurance will also get a prize.

$>$ You are allowed to 'advise' the subject in your own words after you have red out the text, e.g., you might tell the subject to consider how he/she would feel if he/she had not bought insurance and had thrown a ' 6 '.

$>$ Subjects must fill out the sheet themselves

$>$ Whilst the buyer is filling out their sheet you are now only allowed to talk if the subject asks a question or makes inconsistent choices, e.g., switch between insurance and no insurance twice.

$>$ If the subject requires prompting for decisions to be consistent please tick the " $r$ "-box for revised - at the bottom of decision sheet 2.

$>$ When all choices are made, ask the participant to throw the die. Enter the thrown number in the box at the bottom of the decision sheet. 
$>$ Ensure you have the correct decision sheet 2 for the buyer (i.e. the arts, atls, sp1-2 etc. as derived from the sheet 1 answers) and make sure you encourage the subject to read the questions and smallprint carefully.

Now you are facing a decision situation in which your chosen item does not figure.

Your income depends on your throw of the die. If you roll a '6' your income will be zero.

Otherwise your income is $£ 4,000$.

You can now buy an income protection policy. If you buy an income protection policy and you throw

- a '6' the policy pays you $£ 1,500$ to compensate for the loss of income.

- any other number your income is $£ 4,000$ minus the insurance premium.

In successive questions the premium is increased so you have to decide when it is sufficiently high that not taking insurance becomes the preferred option.

We also provide the payout percentage for each policy. This is the percentage of the insurance company's premium income that on average it pays out to policyholders to compensate for their losses.

For example, a payout percentage of $15 \%$ means that for every pound of premium income, on average the insurance company pays out 15 pence to policy holders.

I am required to tell you that in addition to my payment per interview I get a bonus depending on how much insurance I sell (i.e. the number of ticked insurance boxes I hand in). The salesperson who sells the most insurance will also get a prize.

> You are allowed to 'advise' the subject in your own words after you have red out the text, e.g., you might tell the subject to consider how he/she would feel if he/she had not bought insurance and had thrown a ' 6 '.

$>$ Subjects must fill out the sheet themselves

$>$ Whilst the buyer is filling out their sheet you are now only allowed to talk if the subject asks a question or makes inconsistent choices, e.g., switch between insurance and no insurance twice.

$>$ If the subject requires prompting for decisions to be consistent please tick the " $r$ "-box for revised - at the bottom of decision sheet 2.

$>$ When all choices are made, ask the participant to throw the die. Enter the thrown number in the box at the bottom of the decision sheet. 


\section{Sp5-6}

$>$ Ensure you have the correct decision sheet 2 for the buyer (i.e. the arts, atls, sp1-2 etc. as derived from the sheet 1 answers) and make sure you encourage the subject to read the questions and smallprint carefully.

Now you are facing a decision situation in which your chosen item does not figure.

Your income depends on your throw of the die. If you roll a '6' your income will be zero.

Otherwise your income is $£ 4,250$.

You can now buy an income protection policy. If you buy an income protection policy and you throw

- a ' 6 ' the policy pays you $£ 1,750$ to compensate for the loss of income.

- any other number your income is $£ 4,250$ minus the insurance premium.

In successive questions the premium is increased so you have to decide when it is sufficiently high that not taking insurance becomes the preferred option.

We also provide the payout percentage for each policy. This is the percentage of the insurance company's premium income that on average it pays out to policyholders to compensate for their losses.

For example, a payout percentage of $15 \%$ means that for every pound of premium income, on average the insurance company pays out 15 pence to policy holders.

I am required to tell you that in addition to my payment per interview I get a bonus depending on how much insurance I sell (i.e. the number of ticked insurance boxes I hand in). The salesperson who sells the most insurance will also get a prize.

> You are allowed to 'advise' the subject in your own words after you have red out the text, e.g., you might tell the subject to consider how he/she would feel if he/she had not bought insurance and had thrown a ' 6 '.

$>$ Subjects must fill out the sheet themselves

$>$ Whilst the buyer is filling out their sheet you are now only allowed to talk if the subject asks a question or makes inconsistent choices, e.g., switch between insurance and no insurance twice.

$>$ If the subject requires prompting for decisions to be consistent please tick the " $r$ "-box for revised - at the bottom of decision sheet 2.

$>$ When all choices are made, ask the participant to throw the die. Enter the thrown number in the box at the bottom of the decision sheet. 


\section{Sp6-7}

$>$ Ensure you have the correct decision sheet 2 for the buyer (i.e. the arts, atls, sp1-2 etc. as derived from the sheet 1 answers) and make sure you encourage the subject to read the questions and smallprint carefully.

Now you are facing a decision situation in which your chosen item does not figure.

Your income depends on your throw of the die. If you roll a '6' your income will be zero.

Otherwise your income is $£ 4,500$.

You can now buy an income protection policy. If you buy an income protection policy and you throw

- a ' 6 ' the policy pays you £2,000 to compensate for the loss of income.

- any other number your income is $£ 4,500$ minus the insurance premium.

In successive questions the premium is increased so you have to decide when it is sufficiently high that not taking insurance becomes the preferred option

We also provide the payout percentage for each policy. This is the percentage of the insurance company's premium income that on average it pays out to policyholders to compensate for their losses.

For example, a payout percentage of $15 \%$ means that for every pound of premium income, on average the insurance company pays out 15 pence to policy holders.

I am required to tell you that in addition to my payment per interview I get a bonus depending on how much insurance I sell (i.e. the number of ticked insurance boxes I hand in). The salesperson who sells the most insurance will also get a prize.

$>$ You are allowed to 'advise' the subject in your own words after you have red out the text, e.g., you might tell the subject to consider how he/she would feel if he/she had not bought insurance and had thrown a ' 6 '.

$>$ Subjects must fill out the sheet themselves

$>$ Whilst the buyer is filling out their sheet you are now only allowed to talk if the subject asks a question or makes inconsistent choices, e.g., switch between insurance and no insurance twice.

$>$ If the subject requires prompting for decisions to be consistent please tick the " $r$ "-box for revised - at the bottom of decision sheet 2.

$>$ When all choices are made, ask the participant to throw the die. Enter the thrown number in the box at the bottom of the decision sheet. 


\section{Sp7-8}

$>$ Ensure you have the correct decision sheet 2 for the buyer (i.e. the arts, atls, sp1-2 etc. as derived from the sheet 1 answers) and make sure you encourage the subject to read the questions and smallprint carefully.

Now you are facing a decision situation in which your chosen item does not figure.

Your income depends on your throw of the die. If you roll a '6' your income will be zero.

Otherwise your income is $£ 4,750$.

You can now buy an income protection policy. If you buy an income protection policy and you throw

- a '6' the policy pays you £2,250 to compensate for the loss of income.

- any other number your income is $£ 4,750$ minus the insurance premium.

In successive questions the premium is increased so you have to decide when it is sufficiently high that not taking insurance becomes the preferred option.

We also provide the payout percentage for each policy. This is the percentage of the insurance company's premium income that on average it pays out to policyholders to compensate for their losses.

For example, a payout percentage of $15 \%$ means that for every pound of premium income, on average the insurance company pays out 15 pence to policy holders.

I am required to tell you that in addition to my payment per interview I get a bonus depending on how much insurance I sell (i.e. the number of ticked insurance boxes I hand in). The salesperson who sells the most insurance will also get a prize.

> You are allowed to 'advise' the subject in your own words after you have red out the text, e.g., you might tell the subject to consider how he/she would feel if he/she had not bought insurance and had thrown a ' 6 '.

$>$ Subjects must fill out the sheet themselves

> Whilst the buyer is filling out their sheet you are now only allowed to talk if the subject asks a question or makes inconsistent choices, e.g., switch between insurance and no insurance twice.

$>$ If the subject requires prompting for decisions to be consistent please tick the " $r$ "-box for revised - at the bottom of decision sheet 2.

$>$ When all choices are made, ask the participant to throw the die. Enter the thrown number in the box at the bottom of the decision sheet. 


\section{Sp8-9}

$>$ Ensure you have the correct decision sheet 2 for the buyer (i.e. the arts, atls, sp1-2 etc. as derived from the sheet 1 answers) and make sure you encourage the subject to read the questions and smallprint carefully.

Now you are facing a decision situation in which your chosen item does not figure.

Your income depends on your throw of the die. If you roll a '6' your income will be zero.

Otherwise your income is $£ 5,000$.

You can now buy an income protection policy. If you buy an income protection policy and you throw

- a ' 6 ' the policy pays you £2,500 to compensate for the loss of income.

- any other number your income is $£ 5,000$ minus the insurance premium.

In successive questions the premium is increased so you have to decide when it is sufficiently high that not taking insurance becomes the preferred option.

We also provide the payout percentage for each policy. This is the percentage of the insurance company's premium income that on average it pays out to policyholders to compensate for their losses.

For example, a payout percentage of $15 \%$ means that for every pound of premium income, on average the insurance company pays out 15 pence to policy holders.

I am required to tell you that in addition to my payment per interview I get a bonus depending on how much insurance I sell (i.e. the number of ticked insurance boxes I hand in). The salesperson who sells the most insurance will also get a prize.

> You are allowed to 'advise' the subject in your own words after you have red out the text, e.g., you might tell the subject to consider how he/she would feel if he/she had not bought insurance and had thrown a ' 6 '.

$>$ Subjects must fill out the sheet themselves

$>$ Whilst the buyer is filling out their sheet you are now only allowed to talk if the subject asks a question or makes inconsistent choices, e.g., switch between insurance and no insurance twice.

$>$ If the subject requires prompting for decisions to be consistent please tick the " $r$ "-box for revised - at the bottom of decision sheet 2.

$>$ When all choices are made, ask the participant to throw the die. Enter the thrown number in the box at the bottom of the decision sheet. 
$>$ Ensure you have the correct decision sheet 2 for the buyer (i.e. the arts, atls, sp1-2 etc. as derived from the sheet 1 answers) and make sure you encourage the subject to read the questions and smallprint carefully.

Now you are facing a decision situation in which your chosen item does not figure.

Your income depends on your throw of the die. If you roll a '6' your income will be zero.

Otherwise your income is $£ 5,250$.

You can now buy an income protection policy. If you buy an income protection policy and you throw

- a '6' the policy pays you £2,750 to compensate for the loss of income.

- any other number your income is $£ 5,250$ minus the insurance premium.

In successive questions the premium is increased so you have to decide when it is sufficiently high that not taking insurance becomes the preferred option.

We also provide the payout percentage for each policy. This is the percentage of the insurance company's premium income that on average it pays out to policyholders to compensate for their losses.

For example, a payout percentage of $15 \%$ means that for every pound of premium income, on average the insurance company pays out 15 pence to policy holders.

I am required to tell you that in addition to my payment per interview I get a bonus depending on how much insurance I sell (i.e. the number of ticked insurance boxes I hand in). The salesperson who sells the most insurance will also get a prize.

$>$ You are allowed to 'advise' the subject in your own words after you have red out the text, e.g., you might tell the subject to consider how he/she would feel if he/she had not bought insurance and had thrown a ' 6 '.

$>$ Subjects must fill out the sheet themselves

$>$ Whilst the buyer is filling out their sheet you are now only allowed to talk if the subject asks a question or makes inconsistent choices, e.g., switch between insurance and no insurance twice.

$>$ If the subject requires prompting for decisions to be consistent please tick the " $r$ "-box for revised - at the bottom of decision sheet 2.

$>$ When all choices are made, ask the participant to throw the die. Enter the thrown number in the box at the bottom of the decision sheet. 


\section{Sp10-11}

$>$ Ensure you have the correct decision sheet 2 for the buyer (i.e. the arts, atls, sp1-2 etc. as derived from the sheet 1 answers) and make sure you encourage the subject to read the questions and smallprint carefully.

Now you are facing a decision situation in which your chosen item does not figure.

Your income depends on your throw of the die. If you roll a '6' your income will be zero.

Otherwise your income is $£ 5,500$.

You can now buy an income protection policy. If you buy an income protection policy and you throw

- a ' 6 ' the policy pays you $£ 3,000$ to compensate for the loss of income.

- any other number your income is $£ 5,500$ minus the insurance premium.

In successive questions the premium is increased so you have to decide when it is sufficiently high that not taking insurance becomes the preferred option.

We also provide the payout percentage for each policy. This is the percentage of the insurance company's premium income that on average it pays out to policyholders to compensate for their losses.

For example, a payout percentage of $15 \%$ means that for every pound of premium income, on average the insurance company pays out 15 pence to policy holders.

I am required to tell you that in addition to my payment per interview I get a bonus depending on how much insurance I sell (i.e. the number of ticked insurance boxes I hand in). The salesperson who sells the most insurance will also get a prize.

$>$ You are allowed to 'advise' the subject in your own words after you have red out the text, e.g., you might tell the subject to consider how he/she would feel if he/she had not bought insurance and had thrown a ' 6 '.

$>$ Subjects must fill out the sheet themselves

$>$ Whilst the buyer is filling out their sheet you are now only allowed to talk if the subject asks a question or makes inconsistent choices, e.g., switch between insurance and no insurance twice.

$>$ If the subject requires prompting for decisions to be consistent please tick the " $r$ "-box for revised - at the bottom of decision sheet 2.

$>$ When all choices are made, ask the participant to throw the die. Enter the thrown number in the box at the bottom of the decision sheet. 


\section{atls: ('all ticks on the left-hand side')}

$>$ Ensure you have the correct decision sheet 2 for the buyer (i.e. the arts, atls, sp1-2 etc. as derived from the sheet 1 answers) and make sure you encourage the subject to read the questions and smallprint carefully.

Now you are facing a decision situation in which your chosen item does not figure.

Your income depends on your throw of the die. If you roll a '6' your income will be zero.

Otherwise your income is $£ 5,750$.

You can now buy an income protection policy. If you buy an income protection policy and you throw

- a ' 6 ' the policy pays you $£ 3,250$ to compensate for the loss of income.

- any other number your income is $£ 5,750$ minus the insurance premium.

In successive questions the premium is increased so you have to decide when it is sufficiently high that not taking insurance becomes the preferred option.

We also provide the payout percentage for each policy. This is the percentage of the insurance company's premium income that on average it pays out to policyholders to compensate for their losses.

For example, a payout percentage of $15 \%$ means that for every pound of premium income, on average the insurance company pays out 15 pence to policy holders.

I am required to tell you that in addition to my payment per interview I get a bonus depending on how much insurance I sell (i.e. the number of ticked insurance boxes I hand in). The salesperson who sells the most insurance will also get a prize.

> You are allowed to 'advise' the subject in your own words after you have red out the text, e.g., you might tell the subject to consider how he/she would feel if he/she had not bought insurance and had thrown a ' 6 '.

$>$ Subjects must fill out the sheet themselves

$>$ Whilst the buyer is filling out their sheet you are now only allowed to talk if the subject asks a question or makes inconsistent choices, e.g., switch between insurance and no insurance twice.

$>$ If the subject requires prompting for decisions to be consistent please tick the " $r$ "-box for revised - at the bottom of decision sheet 2.

$>$ When all choices are made, ask the participant to throw the die. Enter the thrown number in the box at the bottom of the decision sheet. 


\section{SHEET 3:}

$>$ Now you have to provide the participant with the right decision sheet 3. There are different versions of the decision sheet 3 , i.e., one for each “switchpoint” from decision sheet 1 . The acronyms will help you to find the right ones.

\section{HAND SHEET 3 TO BUYER \& READ OUT FOLLOWING TEXT TO THEM}

The situation in the next set of questions is that you have taken out a loan to buy your selected item. You are expecting an income that is high enough to repay the loan with $£ 2,500$ left over. However, there is a chance that, due to bad luck, you will have no income at all and will be unable to repay the loan. The lender will then repossess the item. So you end up with no income and no item. To protect against repossessing the item, the lender offers you payment protection insurance. To enable you to pay the premium on the insurance, which is due immediately, the lender will increase the loan. In the event of losing your income, the insurance pays off the loan (including the extra repayment for the insurance premium), so at least you get to keep the item.

After you have answered the questions on the next page about whether you would choose to buy insurance, you will throw a die to determine your income. Throwing a six represents bad luck i.e. your income is zero. Throwing any other number gives you the high income. So choosing insurance means you get to keep the item even if you throw a six but if you do not throw a six there is less money left over after you have repaid the larger loan.

The next five questions ask if you want to buy insurance. Successive questions increase the insurance premium and hence the size of the loan repayment if you choose to insure, but that is all that differs between them. In each case we specify what you will end up with for each choice and how it depends on the number you throw.

Again I am required to tell you that my compensation depends on how much insurance I sell. 


\section{SHEET 3:}

You are now allowed to 'advise' the subject in your own words, e.g., you might tell the subject to consider how he/she would feel if he/she had not bought insurance and had thrown a '6'.

Make sure you encourage the subject to read the questions and smallprint carefully. Subjects must fill out this sheet themselves.

Whilst the buyer is filling their sheet out, you are now only allowed to talk if they ask a question or if they make inconsistent choices, e.g. they switch between insurance and no insurance twice.

\section{If the subject requires prompting for decisions to be consistent please} tick the "r"-box - for revised - at the bottom of decision sheet 3.

When all choices are made, ask the participant to throw the die. Enter the thrown number in the box at the bottom of the decision sheet.

Now ask the participant to pick a number from the bag and note down the number on the cover of the decision sheet. 


\section{Appendix B}

Decision sheet for buyers

\section{Decision sheets $\mathbf{H}$}

\section{Date:}

Time:

Participant's name:

Participant's number:

Seller’s name:

Seller’s number:

Participant has chosen the following item:

Number drawn: 


\section{Sheet 1}

Please tick ONE of the boxes for EACH question indicating your choice.

I prefer:

1) $\square$ My chosen item

OR

$£ 625$

2) $\square$ My chosen item

OR

$£ 875$

3) $\square$ My chosen item

OR

$£ 1,125$

4) $\square$ My chosen item

OR

$£ 1,375$

5) $\square$ My chosen item

OR

$£ 1,625$

6) $\square$ My chosen item

OR

$£ 1,875$

7) $\square$ My chosen item

OR

$£ 2,125$

8) $\square$ My chosen item

OR

$£ 2,375$

9) $\square$ My chosen item

OR

$£ 2,625$

10) $\square$ My chosen item

OR

$£ 2,875$

11) $\square$ My chosen item

OR

- 3,125 


\section{Sheet 2}

Please tick ONE of the boxes for EACH question indicating your choice.

The payout percentage is the percentage of insurance company's premium income that on average it pays out to compensate for policyholders' losses.

12) $\square$ no insurance

(i.e. if you throw a ' 6 ' you get nothing and if you throw any other number you get $£ 3,000$ )

\section{$\square$ insurance at premium $£ 111$ (payout percentage 90\%)}

(i.e. if you throw a '6' you get $£ 500$ and if you throw any other number you get $£ 2,889$ )

13) $\square$ no insurance

(i.e. if you throw a ' 6 ' you get nothing and if you throw any other number you get $£ 3,000$ )

$\square$ insurance at premium $£ 143 \quad$ (payout percentage 70\%)

(i.e. if you throw a '6' you get $£ 500$ and if you throw any other number you get $£ 2,857$ )

14) $\square$ no insurance

(i.e. if you throw a ' 6 ' you get nothing and if you throw any other number you get $£ 3,000$ )

$\square$ insurance at premium $£ 200 \quad$ (payout percentage 50\%)

(i.e. if you throw a '6' you get $£ 500$ and if you throw any other number you get $£ 2,800$ )

15) $\square$ no insurance

(i.e. if you throw a '6' you get nothing and if you throw any other number you get $£ 3,000$ )

$\square$ insurance at premium £250 (payout percentage 40\%)

(i.e. if you throw a ' 6 ' you get $£ 500$ and if you throw any other number you get $£ 2,750$ )

16) $\square$ no insurance

(i.e. if you throw a ' 6 ' you get nothing and if you throw any other number you get £3,000)

$\square$ insurance at premium $£ 333 \quad$ (payout percentage 30\%)

(i.e. if you throw a '6' you get $£ 500$ and if you throw any other number you get $£ 2,667$ )

Now throw the die.

Outcome of throwing the die:

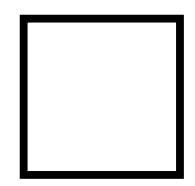




\section{Sheet 2}

Please tick ONE of the boxes for EACH question indicating your choice.

The payout percentage is the percentage of insurance company's premium income that on average it pays out to compensate for policyholders' losses.

12) $\square$ no insurance

(i.e. if you throw a ' 6 ' you get nothing and if you throw any other number you get $£ 3,250$ )

\section{insurance at premium $£ 167 \quad$ (payout percentage 90\%)}

(i.e. if you throw a '6' you get $£ 750$ and if you throw any other number you get $£ 3,083$ )

13) $\square$ no insurance

(i.e. if you throw a ' 6 ' you get nothing and if you throw any other number you get $£ 3,250$ )

$\square$ insurance at premium $£ 214 \quad$ (payout percentage 70\%)

(i.e. if you throw a '6' you get $£ 750$ and if you throw any other number you get $£ 3,036$ )

14) $\square$ no insurance

(i.e. if you throw a ' 6 ' you get nothing and if you throw any other number you get $£ 3,250$ )

$\square$ insurance at premium $£ 300 \quad$ (payout percentage 50\%)

(i.e. if you throw a '6' you get $£ 750$ and if you throw any other number you get $£ 2,950$ )

15) $\square$ no insurance

(i.e. if you throw a ' 6 ' you get nothing and if you throw any other number you get $£ 3,250$ )

$\square$ insurance at premium $£ 375$ (payout percentage 40\%)

(i.e. if you throw a '6' you get $£ 750$ and if you throw any other number you get $£ 2,875$ )

16) $\square$ no insurance

(i.e. if you throw a ' 6 ' you get nothing and if you throw any other number you get $£ 3,250$ )

$\square$ insurance at premium $£ 500 \quad$ (payout percentage 30\%)

(i.e. if you throw a ' 6 ' you get $£ 750$ and if you throw any other number you get $£ 2,750$ )

Now throw the die.

Outcome of throwing the die:

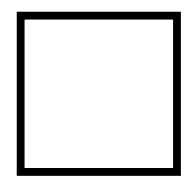




\section{Sheet 2}

Please tick ONE of the boxes for EACH question indicating your choice.

The payout percentage is the percentage of insurance company's premium income that on average it pays out to compensate for policyholders' losses.

12) $\square$ no insurance

(i.e. if you throw a ' 6 ' you get nothing and if you throw any other number you get $£ 3,500$ )

\section{insurance at premium £222 (payout percentage 90\%)}

(i.e. if you throw a '6' you get $£ 1,000$ and if you throw any other number you get $£ 3,278$ )

13) $\square$ no insurance

(i.e. if you throw a ' 6 ' you get nothing and if you throw any other number you get $£ 3,500$ )

$\square$ insurance at premium £286 (payout percentage 70\%)

(i.e. if you throw a ' 6 ' you get $£ 1,000$ and if you throw any other number you get $£ 3,214$ )

14) $\square$ no insurance

(i.e. if you throw a ' 6 ' you get nothing and if you throw any other number you get $£ 3,500$ )

$\square$ insurance at premium $£ 400 \quad$ (payout percentage 50\%)

(i.e. if you throw a '6' you get $£ 1,000$ and if you throw any other number you get $£ 3,100$ )

15) $\square$ no insurance

(i.e. if you throw a ' 6 ' you get nothing and if you throw any other number you get $£ 3,500$ )

$\square$ insurance at premium $£ 500 \quad$ (payout percentage 40\%)

(i.e. if you throw a ' 6 ' you get $£ 1,000$ and if you throw any other number you get $£ 3,000$ )

16) $\square$ no insurance

(i.e. if you throw a ' 6 ' you get nothing and if you throw any other number you get $£ 3,500$ )

$\square$ insurance at premium £667 (payout percentage 30\%)

(i.e. if you throw a ' 6 ' you get $£ 1,000$ and if you throw any other number you get $£ 2,833$ )

Now throw the die.

Outcome of throwing the die: 


\section{Sheet 2}

Please tick ONE of the boxes for EACH question indicating your choice.

The payout percentage is the percentage of insurance company's premium income that on average it pays out to compensate for policyholders' losses.

12) $\square$ no insurance

(i.e. if you throw a ' 6 ' you get nothing and if you throw any other number you get $£ 3,750$ )

\section{insurance at premium £278 (payout percentage 90\%)}

(i.e. if you throw a '6' you get $£ 1,250$ and if you throw any other number you get $£ 3,472$ )

13) $\square$ no insurance

(i.e. if you throw a ' 6 ' you get nothing and if you throw any other number you get $£ 3,750$ )

$\square$ insurance at premium $£ 357 \quad$ (payout percentage 70\%)

(i.e. if you throw a ' 6 ' you get $£ 1,250$ and if you throw any other number you get $£ 3,393$ )

14) $\square$ no insurance

(i.e. if you throw a ' 6 ' you get nothing and if you throw any other number you get $£ 3,750$ )

$\square$ insurance at premium $£ 500 \quad$ (payout percentage 50\%)

(i.e. if you throw a ' 6 ' you get $£ 1,250$ and if you throw any other number you get $£ 3,250$ )

15) $\square$ no insurance

(i.e. if you throw a ' 6 ' you get nothing and if you throw any other number you get £3,750)

$\square$ insurance at premium £625 (payout percentage 40\%)

(i.e. if you throw a ' 6 ' you get $£ 1,250$ and if you throw any other number you get $£ 3,125$ )

16) $\square$ no insurance

(i.e. if you throw a ' 6 ' you get nothing and if you throw any other number you get $£ 3,750$ )

$\square$ insurance at premium £833 (payout percentage 30\%)

(i.e. if you throw a '6' you get $£ 1,250$ and if you throw any other number you get $£ 2,917$ )

Now throw the die.

Outcome of throwing the die: 


\section{Sheet 2}

Please tick ONE of the boxes for EACH question indicating your choice.

The payout percentage is the percentage of insurance company's premium income that on average it pays out to compensate for policyholders' losses.

12) $\square$ no insurance

(i.e. if you throw a ' 6 ' you get nothing and if you throw any other number you get $£ 4,000$ )

\section{$\square$ insurance at premium £333 (payout percentage 90\%)}

(i.e. if you throw a ' 6 ' you get $£ 1,500$ and if you throw any other number you get $£ 3,667$ )

13) $\square$ no insurance

(i.e. if you throw a ' 6 ' you get nothing and if you throw any other number you get $£ 4,000$ )

$\square$ insurance at premium $£ 429 \quad$ (payout percentage 70\%)

(i.e. if you throw a ' 6 ' you get $£ 1,500$ and if you throw any other number you get $£ 3,571$ )

14) $\square$ no insurance

(i.e. if you throw a ' 6 ' you get nothing and if you throw any other number you get $£ 4,000$ )

$\square$ insurance at premium $£ 600 \quad$ (payout percentage 50\%)

(i.e. if you throw a '6' you get $£ 1,500$ and if you throw any other number you get $£ 3,400$ )

15) $\square$ no insurance

(i.e. if you throw a ' 6 ' you get nothing and if you throw any other number you get $£ 4,000$ )

$\square$ insurance at premium $£ 750 \quad$ (payout percentage 40\%)

(i.e. if you throw a ' 6 ' you get $£ 1,500$ and if you throw any other number you get $£ 3,250$ )

16) $\square$ no insurance

(i.e. if you throw a ' 6 ' you get nothing and if you throw any other number you get $£ 4,000$ )

$\square$ insurance at premium $£ 1,000$ (payout percentage 30\%)

(i.e. if you throw a ' 6 ' you get $£ 1,500$ and if you throw any other number you get $£ 3,000$ )

Now throw the die.

Outcome of throwing the die: 


\section{Sheet 2}

Please tick ONE of the boxes for EACH question indicating your choice.

The payout percentage is the percentage of insurance company's premium income that on average it pays out to compensate for policyholders' losses.

12) $\square$ no insurance

(i.e. if you throw a ' 6 ' you get nothing and if you throw any other number you get $£ 4,250$ )

\section{insurance at premium £389 (payout percentage 90\%)}

(i.e. if you throw a '6' you get $£ 1,750$ and if you throw any other number you get $£ 3,861$ )

13) $\square$ no insurance

(i.e. if you throw a ' 6 ' you get nothing and if you throw any other number you get $£ 4,250$ )

$\square$ insurance at premium $£ 500 \quad$ (payout percentage 70\%)

(i.e. if you throw a ' 6 ' you get $£ 1,750$ and if you throw any other number you get $£ 3,750$ )

14) $\square$ no insurance

(i.e. if you throw a ' 6 ' you get nothing and if you throw any other number you get $£ 4,250$ )

$\square$ insurance at premium $£ 700 \quad$ (payout percentage 50\%)

(i.e. if you throw a ' 6 ' you get $£ 1,750$ and if you throw any other number you get $£ 3,550$ )

15) $\square$ no insurance

(i.e. if you throw a ' 6 ' you get nothing and if you throw any other number you get $£ 4,250$ )

$\square$ insurance at premium £875 (payout percentage 40\%)

(i.e. if you throw a ' 6 ' you get $£ 1,750$ and if you throw any other number you get $£ 3,375$ )

16) $\square$ no insurance

(i.e. if you throw a ' 6 ' you get nothing and if you throw any other number you get $£ 4,250$ )

$\square$ insurance at premium $£ 1,167$ (payout percentage 30\%)

(i.e. if you throw a ' 6 ' you get $£ 1,750$ and if you throw any other number you get $£ 3,083$ )

Now throw the die.

Outcome of throwing the die: 


\section{Sheet 2}

Please tick ONE of the boxes for EACH question indicating your choice.

The payout percentage is the percentage of insurance company's premium income that on average it pays out to compensate for policyholders' losses.

12) $\square$ no insurance

(i.e. if you throw a ' 6 ' you get nothing and if you throw any other number you get $£ 4,500$ )

\section{$\square$ insurance at premium $£ 444$ (payout percentage 90\%)}

(i.e. if you throw a ' 6 ' you get $£ 2,000$ and if you throw any other number you get $£ 4,056$ )

13) $\square$ no insurance

(i.e. if you throw a ' 6 ' you get nothing and if you throw any other number you get $£ 4,500$ )

$\square$ insurance at premium $£ 571 \quad$ (payout percentage 70\%)

(i.e. if you throw a ' 6 ' you get $£ 2,000$ and if you throw any other number you get $£ 3,929$ )

14) $\square$ no insurance

(i.e. if you throw a ' 6 ' you get nothing and if you throw any other number you get $£ 4,500$ )

$\square$ insurance at premium $£ 800 \quad$ (payout percentage 50\%)

(i.e. if you throw a '6' you get $£ 2,000$ and if you throw any other number you get $£ 3,700$ )

15) $\square$ no insurance

(i.e. if you throw a ' 6 ' you get nothing and if you throw any other number you get $£ 4,500$ )

$\square$ insurance at premium $£ 1,000$ (payout percentage 40\%)

(i.e. if you throw a ' 6 ' you get $£ 2,000$ and if you throw any other number you get $£ 3,500$ )

16) $\square$ no insurance

(i.e. if you throw a ' 6 ' you get nothing and if you throw any other number you get $£ 4,500$ )

$\square$ insurance at premium $£ 1,333$ (payout percentage 30\%)

(i.e. if you throw a ' 6 ' you get $£ 2,000$ and if you throw any other number you get $£ 3,167$ )

Now throw the die.

Outcome of throwing the die: 


\section{Sheet 2}

Please tick ONE of the boxes for EACH question indicating your choice.

The payout percentage is the percentage of insurance company's premium income that on average it pays out to compensate for policyholders' losses.

12) $\square$ no insurance

(i.e. if you throw a ' 6 ' you get nothing and if you throw any other number you get $£ 4,750$ )
insurance at premium $£ 500$
(payout percentage 90\%)

(i.e. if you throw a '6' you get $£ 2,250$ and if you throw any other number you get $£ 4,250$ )

13) $\square$ no insurance

(i.e. if you throw a ' 6 ' you get nothing and if you throw any other number you get $£ 4,750$ )

$\square$ insurance at premium $£ 643 \quad$ (payout percentage 70\%)

(i.e. if you throw a ' 6 ' you get $£ 2,250$ and if you throw any other number you get $£ 4,107$ )

14) $\square$ no insurance

(i.e. if you throw a ' 6 ' you get nothing and if you throw any other number you get $£ 4,750$ )

$\square$ insurance at premium $£ 900 \quad$ (payout percentage 50\%)

(i.e. if you throw a ' 6 ' you get $£ 2,250$ and if you throw any other number you get $£ 3,850$ )

15) $\square$ no insurance

(i.e. if you throw a ' 6 ' you get nothing and if you throw any other number you get $£ 4,750$ )

$\square$ insurance at premium $£ 1,125$ (payout percentage 40\%)

(i.e. if you throw a ' 6 ' you get $£ 2,250$ and if you throw any other number you get $£ 3,625$ )

16) $\square$ no insurance

(i.e. if you throw a ' 6 ' you get nothing and if you throw any other number you get $£ 4,750$ )

$\square$ insurance at premium $£ 1,500$ (payout percentage 30\%)

(i.e. if you throw a ' 6 ' you get $£ 2,250$ and if you throw any other number you get $£ 3,250$ )

Now throw the die.

Outcome of throwing the die: 


\section{Sheet 2}

Please tick ONE of the boxes for EACH question indicating your choice.

The payout percentage is the percentage of insurance company's premium income that on average it pays out to compensate for policyholders' losses.

12) $\square$ no insurance

(i.e. if you throw a ' 6 ' you get nothing and if you throw any other number you get $£ 5,000$ )

\section{$\square$ insurance at premium £556 (payout percentage 90\%)}

(i.e. if you throw a '6' you get $£ 2,500$ and if you throw any other number you get $£ 4,444$ )

13) $\square$ no insurance

(i.e. if you throw a ' 6 ' you get nothing and if you throw any other number you get $£ 5,000$ )

$\square$ insurance at premium $£ 714$ (payout percentage 70\%)

(i.e. if you throw a ' 6 ' you get $£ 2,500$ and if you throw any other number you get $£ 4,286$ )

14) $\square$ no insurance

(i.e. if you throw a ' 6 ' you get nothing and if you throw any other number you get $£ 5,000$ )

$\square$ insurance at premium $£ 1,000$ (payout percentage 50\%)

(i.e. if you throw a '6' you get $£ 2,500$ and if you throw any other number you get $£ 4,000$ )

15) $\square$ no insurance

(i.e. if you throw a ' 6 ' you get nothing and if you throw any other number you get £5,000)

$\square$ insurance at premium $£ 1,250$ (payout percentage 40\%)

(i.e. if you throw a ' 6 ' you get $£ 2,500$ and if you throw any other number you get $£ 3,750$ )

16) $\square$ no insurance

(i.e. if you throw a ' 6 ' you get nothing and if you throw any other number you get $£ 5,000$ )

$\square$ insurance at premium $£ 1,667$ (payout percentage 30\%)

(i.e. if you throw a ' 6 ' you get $£ 2,500$ and if you throw any other number you get $£ 3,333$ )

Now throw the die.

Outcome of throwing the die: 


\section{Sheet 2}

Please tick ONE of the boxes for EACH question indicating your choice.

The payout percentage is the percentage of insurance company's premium income that on average it pays out to compensate for policyholders' losses.

12) $\square$ no insurance

(i.e. if you throw a ' 6 ' you get nothing and if you throw any other number you get $£ 5,250$ )

\section{insurance at premium $£ 611$ (payout percentage 90\%)}

(i.e. if you throw a '6' you get $£ 2,750$ and if you throw any other number you get $£ 4,639$ )

13) $\square$ no insurance

(i.e. if you throw a ' 6 ' you get nothing and if you throw any other number you get £5,250)

$\square$ insurance at premium $£ 786 \quad$ (payout percentage 70\%)

(i.e. if you throw a ' 6 ' you get $£ 2,750$ and if you throw any other number you get $£ 4,464$ )

14) $\square$ no insurance

(i.e. if you throw a ' 6 ' you get nothing and if you throw any other number you get £5,250)

$\square$ insurance at premium $£ 1,100$ (payout percentage 50\%)

(i.e. if you throw a '6' you get $£ 2,750$ and if you throw any other number you get $£ 4,150$ )

14) $\square$ no insurance

(i.e. if you throw a '6' you get nothing and if you throw any other number you get $£ 5,250$ )

$\square$ insurance at premium $£ 1,375$ (payout percentage 40\%)

(i.e. if you throw a '6' you get $£ 2,750$ and if you throw any other number you get $£ 3,875$ )

16) $\square$ no insurance

(i.e. if you throw a ' 6 ' you get nothing and if you throw any other number you get $£ 5,250$ )

$\square$ insurance at premium $£ 1,833$ (payout percentage 30\%)

(i.e. if you throw a ' 6 ' you get $£ 2,750$ and if you throw any other number you get $£ 3,417$ )

Now throw the die.

Outcome of throwing the die:

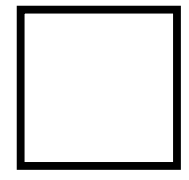




\section{Sheet 2}

Please tick ONE of the boxes for EACH question indicating your choice.

The payout percentage is the percentage of insurance company's premium income that on average it pays out to compensate for policyholders' losses.

12) $\square$ no insurance

(i.e. if you throw a ' 6 ' you get nothing and if you throw any other number you get $£ 5,500$ )

\section{insurance at premium £667 (payout percentage 90\%)}

(i.e. if you throw a '6' you get $£ 3,000$ and if you throw any other number you get $£ 4,833$ )

13) $\square$ no insurance

(i.e. if you throw a '6' you get nothing and if you throw any other number you get £5,500)

$\square$ insurance at premium $£ 857 \quad$ (payout percentage 70\%)

(i.e. if you throw a ' 6 ' you get $£ 3,000$ and if you throw any other number you get $£ 4,643$ )

14) $\square$ no insurance

(i.e. if you throw a ' 6 ' you get nothing and if you throw any other number you get $£ 5,500$ )

$\square$ insurance at premium $£ 1,200$ (payout percentage 50\%)

(i.e. if you throw a ' 6 ' you get $£ 3,000$ and if you throw any other number you get $£ 4,300$ )

15) $\square$ no insurance

(i.e. if you throw a '6' you get nothing and if you throw any other number you get $£ 5,500$ )

$\square$ insurance at premium $£ 1,500$ (payout percentage 40\%)

(i.e. if you throw a '6' you get $£ 3,000$ and if you throw any other number you get $£ 4,000$ )

16) $\square$ no insurance

(i.e. if you throw a ' 6 ' you get nothing and if you throw any other number you get $£ 5,500$ )

$\square$ insurance at premium $£ 2,000$ (payout percentage 30\%)

(i.e. if you throw a ' 6 ' you get $£ 3,000$ and if you throw any other number you get $£ 3,500$ )

Now throw the die.

Outcome of throwing the die:

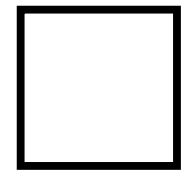




\section{Sheet 2}

Please tick ONE of the boxes for EACH question indicating your choice.

The payout percentage is the percentage of insurance company's premium income that on average it pays out to compensate for policyholders' losses.

12) $\square$ no insurance

(i.e. if you throw a ' 6 ' you get nothing and if you throw any other number you get $£ 5,750$ )

\section{$\square$ insurance at premium $£ 722$ (payout percentage 90\%)}

(i.e. if you throw a '6' you get $£ 3,250$ and if you throw any other number you get $£ 5,028$ )

13) $\square$ no insurance

(i.e. if you throw a ' 6 ' you get nothing and if you throw any other number you get $£ 5,750$ )

$\square$ insurance at premium £929 (payout percentage 70\%)

(i.e. if you throw a ' 6 ' you get $£ 3,250$ and if you throw any other number you get $£ 4,821$ )

14) $\square$ no insurance

(i.e. if you throw a ' 6 ' you get nothing and if you throw any other number you get $£ 5,750$ )

$\square$ insurance at premium $£ 1,300$ (payout percentage 50\%)

(i.e. if you throw a ' 6 ' you get $£ 3,250$ and if you throw any other number you get $£ 4,450$ )

15) $\square$ no insurance

(i.e. if you throw a ' 6 ' you get nothing and if you throw any other number you get £5,750)

$\square$ insurance at premium $£ 1,625$ (payout percentage 40\%)

(i.e. if you throw a ' 6 ' you get $£ 3,250$ and if you throw any other number you get $£ 4,125$ )

16) $\square$ no insurance

(i.e. if you throw a ' 6 ' you get nothing and if you throw any other number you get $£ 5,750$ )

$\square$ insurance at premium $£ 2,167$ (payout percentage 30\%)

(i.e. if you throw a ' 6 ' you get $£ 3,250$ and if you throw any other number you get $£ 3,583$ )

Now throw the die.

Outcome of throwing the die: 


\section{Sheet 3}

Please tick ONE of the boxes for EACH question indicating your choice.

17) $\square$ no insurance

(i.e. if you throw a '6' you get nothing and if you throw any other number you get your chosen item plus the $£ 2,500$ left after repaying the loan)

\section{insurance which increases the loan repayment by $£ 111$}

(i.e. if you throw a ' 6 ', you get your chosen item but no money and if you throw any other number you get your chosen item plus the $£ 2,389$ left after repaying the loan)

18) $\square$ no insurance

(i.e. if you throw a ' 6 ' you get nothing and if you throw any other number you get your chosen item plus the $£ 2,500$ left after repaying the loan)

\section{insurance which increases the loan repayment by $£ 143$}

(i.e. if you throw a ' 6 ', you get your chosen item but no money and if you throw any other number you get your chosen item plus the $£ 2,357$ left after repaying the loan)

19) $\square$ no insurance

(i.e. if you throw a ' 6 ' you get nothing and if you throw any other number you get your chosen item plus the $£ 2,500$ left after repaying the loan)

\section{insurance which increases the loan repayment by $£ 200$}

(i.e. if you throw a '6', you get your chosen item but no money and if you throw any other number you get your chosen item plus the $£ 2,300$ left after repaying the loan)

20) $\square$ no insurance

(i.e. if you throw a ' 6 ' you get nothing and if you throw any other number you get your chosen item plus the $£ 2,500$ left after repaying the loan)

$\square$ insurance which increases the loan repayment by $£ 250$

(i.e. if you throw a '6', you get your chosen item but no money and if you throw any other number you get your chosen item plus the £2,250 left after repaying the loan)

21) $\square$ no insurance

(i.e. if you throw a ' 6 ' you get nothing and if you throw any other number you get your chosen item plus the $£ 2,500$ left after repaying the loan)

\section{insurance which increases the loan repayment by $£ 333$}

(i.e. if you throw a '6', you get your chosen item but no money and if you throw any other number you get your chosen item plus the £2,167 left after repaying the loan)

Now throw the die.

Outcome of throwing the die:

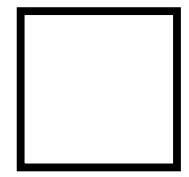




\section{Sheet 3}

Please tick ONE of the boxes for EACH question indicating your choice.

17) $\square$ no insurance

(i.e. if you throw a '6' you get nothing and if you throw any other number you get your chosen item plus the $£ 2,500$ left after repaying the loan)

\section{insurance which increases the loan repayment by $£ 167$}

(i.e. if you throw a ' 6 ', you get your chosen item but no money and if you throw any other number you get your chosen item plus the $£ 2,333$ left after repaying the loan)

18) $\square$ no insurance

(i.e. if you throw a ' 6 ' you get nothing and if you throw any other number you get your chosen item plus the $£ 2,500$ left after repaying the loan)

$\square$ insurance which increases the loan repayment by $£ 214$

(i.e. if you throw a ' 6 ', you get your chosen item but no money and if you throw any other number you get your chosen item plus the £2,286 left after repaying the loan)

19) $\square$ no insurance

(i.e. if you throw a ' 6 ' you get nothing and if you throw any other number you get your chosen item plus the $£ 2,500$ left after repaying the loan)

\section{insurance which increases the loan repayment by $£ 300$}

(i.e. if you throw a '6', you get your chosen item but no money and if you throw any other number you get your chosen item plus the £2,200 left after repaying the loan)

20) $\square$ no insurance

(i.e. if you throw a ' 6 ' you get nothing and if you throw any other number you get your chosen item plus the $£ 2,500$ left after repaying the loan)

$\square$ insurance which increases the loan repayment by $£ 375$

(i.e. if you throw a ' 6 ', you get your chosen item but no money and if you throw any other number you get your chosen item plus the $£ 2,125$ left after repaying the loan)

21) $\square$ no insurance

(i.e. if you throw a ' 6 ' you get nothing and if you throw any other number you get your chosen item plus the $£ 2,500$ left after repaying the loan)

insurance which increases the loan repayment by $£ 500$

(i.e. if you throw a '6', you get your chosen item but no money and if you throw any other number you get your chosen item plus the $£ 2,000$ left after repaying the loan)

Now throw the die.

Outcome of throwing the die:

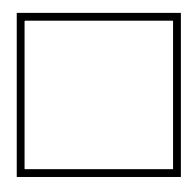




\section{Sheet 3}

Please tick ONE of the boxes for EACH question indicating your choice.

17) $\square$ no insurance

(i.e. if you throw a '6' you get nothing and if you throw any other number you get your chosen item plus the $£ 2,500$ left after repaying the loan)

$\square$ insurance which increases the loan repayment by $£ 222$

(i.e. if you throw a ' 6 ', you get your chosen item but no money and if you throw any other number you get your chosen item plus the $£ 2,278$ left after repaying the loan)

18) $\square$ no insurance

(i.e. if you throw a ' 6 ' you get nothing and if you throw any other number you get your chosen item plus the $£ 2,500$ left after repaying the loan)

$\square$ insurance which increases the loan repayment by $£ 286$

(i.e. if you throw a ' 6 ', you get your chosen item but no money and if you throw any other number you get your chosen item plus the £2,214 left after repaying the loan)

19) $\square$ no insurance

(i.e. if you throw a ' 6 ' you get nothing and if you throw any other number you get your chosen item plus the $£ 2,500$ left after repaying the loan)

insurance which increases the loan repayment by $£ 400$

(i.e. if you throw a '6', you get your chosen item but no money and if you throw any other number you get your chosen item plus the £2,100 left after repaying the loan)

20) $\square$ no insurance

(i.e. if you throw a ' 6 ' you get nothing and if you throw any other number you get your chosen item plus the $£ 2,500$ left after repaying the loan)

$\square$ insurance which increases the loan repayment by $£ 500$

(i.e. if you throw a ' 6 ', you get your chosen item but no money and if you throw any other number you get your chosen item plus the $£ 2,000$ left after repaying the loan)

21) $\square$ no insurance

(i.e. if you throw a ' 6 ' you get nothing and if you throw any other number you get your chosen item plus the $£ 2,500$ left after repaying the loan)

insurance which increases the loan repayment by $£ 667$

(i.e. if you throw a ' 6 ', you get your chosen item but no money and if you throw any other number you get your chosen item plus the $£ 1,833$ left after repaying the loan)

Now throw the die.

Outcome of throwing the die:

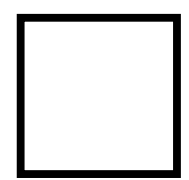




\section{Sheet 3}

Please tick ONE of the boxes for EACH question indicating your choice.

\section{7) $\square$ no insurance}

(i.e. if you throw a '6' you get nothing and if you throw any other number you get your chosen item plus the $£ 2,500$ left after repaying the loan)

\section{insurance which increases the loan repayment by $£ 278$}

(i.e. if you throw a ' 6 ', you get your chosen item but no money and if you throw any other number you get your chosen item plus the $£ 2,222$ left after repaying the loan)

18) $\square$ no insurance

(i.e. if you throw a '6' you get nothing and if you throw any other number you get your chosen item plus the $£ 2,500$ left after repaying the loan)

$\square$ insurance which increases the loan repayment by $£ 357$

(i.e. if you throw a ' 6 ', you get your chosen item but no money and if you throw any other number you get your chosen item plus the $£ 2,143$ left after repaying the loan)

19) $\square$ no insurance

(i.e. if you throw a '6' you get nothing and if you throw any other number you get your chosen item plus the $£ 2,500$ left after repaying the loan)

\section{insurance which increases the loan repayment by $£ 500$}

(i.e. if you throw a '6', you get your chosen item but no money and if you throw any other number you get your chosen item plus the $£ 2,000$ left after repaying the loan)

20) $\square$ no insurance

(i.e. if you throw a '6' you get nothing and if you throw any other number you get your chosen item plus the $£ 2,500$ left after repaying the loan)

$\square$ insurance which increases the loan repayment by $£ 625$

(i.e. if you throw a ' 6 ', you get your chosen item but no money and if you throw any other number you get your chosen item plus the $£ 1,875$ left after repaying the loan)

21) $\square$ no insurance

(i.e. if you throw a ' 6 ' you get nothing and if you throw any other number you get your chosen item plus the $£ 2,500$ left after repaying the loan)

insurance which increases the loan repayment by $£ 833$

(i.e. if you throw a ' 6 ', you get your chosen item but no money and if you throw any other number you get your chosen item plus the $£ 1,667$ left after repaying the loan)

Now throw the die.

Outcome of throwing the die:

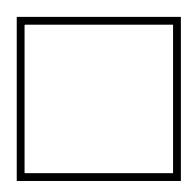




\section{Sheet 3}

Please tick ONE of the boxes for EACH question indicating your choice.

\section{7) $\square$ no insurance}

(i.e. if you throw a '6' you get nothing and if you throw any other number you get your chosen item plus the $£ 2,500$ left after repaying the loan)

\section{insurance which increases the loan repayment by $£ 333$}

(i.e. if you throw a ' 6 ', you get your chosen item but no money and if you throw any other number you get your chosen item plus the $£ 2,167$ left after repaying the loan)

18) $\square$ no insurance

(i.e. if you throw a ' 6 ' you get nothing and if you throw any other number you get your chosen item plus the $£ 2,500$ left after repaying the loan)

$\square$ insurance which increases the loan repayment by $£ 429$

(i.e. if you throw a ' 6 ', you get your chosen item but no money and if you throw any other number you get your chosen item plus the $£ 2,071$ left after repaying the loan)

19) $\square$ no insurance

(i.e. if you throw a ' 6 ' you get nothing and if you throw any other number you get your chosen item plus the $£ 2,500$ left after repaying the loan)

\section{insurance which increases the loan repayment by $£ 600$}

(i.e. if you throw a '6', you get your chosen item but no money and if you throw any other number you get your chosen item plus the $£ 1,900$ left after repaying the loan)

20) $\square$ no insurance

(i.e. if you throw a '6' you get nothing and if you throw any other number you get your chosen item plus the $£ 2,500$ left after repaying the loan)

$\square$ insurance which increases the loan repayment by $£ 750$

(i.e. if you throw a ' 6 ', you get your chosen item but no money and if you throw any other number you get your chosen item plus the $£ 1,750$ left after repaying the loan)

21) $\square$ no insurance

(i.e. if you throw a ' 6 ' you get nothing and if you throw any other number you get your chosen item plus the $£ 2,500$ left after repaying the loan)

insurance which increases the loan repayment by $£ 1,000$

(i.e. if you throw a ' 6 ', you get your chosen item but no money and if you throw any other number you get your chosen item plus the $£ 1,500$ left after repaying the loan)

Now throw the die.

Outcome of throwing the die:

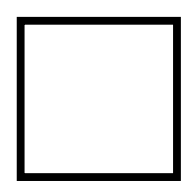




\section{Sheet 3}

Please tick ONE of the boxes for EACH question indicating your choice.

17) $\square$ no insurance

(i.e. if you throw a '6' you get nothing and if you throw any other number you get your chosen item plus the $£ 2,500$ left after repaying the loan)

\section{insurance which increases the loan repayment by $£ 389$}

(i.e. if you throw a ' 6 ', you get your chosen item but no money and if you throw any other number you get your chosen item plus the £2,111 left after repaying the loan)

18) $\square$ no insurance

(i.e. if you throw a ' 6 ' you get nothing and if you throw any other number you get your chosen item plus the $£ 2,500$ left after repaying the loan)

$\square$ insurance which increases the loan repayment by $£ 500$

(i.e. if you throw a ' 6 ', you get your chosen item but no money and if you throw any other number you get your chosen item plus the $£ 2,000$ left after repaying the loan)

19) $\square$ no insurance

(i.e. if you throw a ' 6 ' you get nothing and if you throw any other number you get your chosen item plus the $£ 2,500$ left after repaying the loan)

\section{insurance which increases the loan repayment by $£ 700$}

(i.e. if you throw a '6', you get your chosen item but no money and if you throw any other number you get your chosen item plus the $£ 1,800$ left after repaying the loan)

20) $\square$ no insurance

(i.e. if you throw a ' 6 ' you get nothing and if you throw any other number you get your chosen item plus the $£ 2,500$ left after repaying the loan)

$\square$ insurance which increases the loan repayment by $£ 875$

(i.e. if you throw a ' 6 ', you get your chosen item but no money and if you throw any other number you get your chosen item plus the $£ 1,625$ left after repaying the loan)

21) $\square$ no insurance

(i.e. if you throw a ' 6 ' you get nothing and if you throw any other number you get your chosen item plus the $£ 2,500$ left after repaying the loan)

insurance which increases the loan repayment by $£ 1,167$

(i.e. if you throw a ' 6 ', you get your chosen item but no money and if you throw any other number you get your chosen item plus the $£ 1,333$ left after repaying the loan)

Now throw the die.

Outcome of throwing the die:

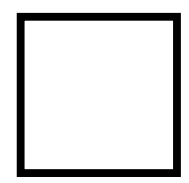




\section{Sheet 3}

Please tick ONE of the boxes for EACH question indicating your choice.

17) $\square$ no insurance

(i.e. if you throw a '6' you get nothing and if you throw any other number you get your chosen item plus the $£ 2,500$ left after repaying the loan)

\section{insurance which increases the loan repayment by $£ 444$}

(i.e. if you throw a ' 6 ', you get your chosen item but no money and if you throw any other number you get your chosen item plus the £2,056 left after repaying the loan)

18) $\square$ no insurance

(i.e. if you throw a ' 6 ' you get nothing and if you throw any other number you get your chosen item plus the $£ 2,500$ left after repaying the loan)

$\square$ insurance which increases the loan repayment by $£ 571$

(i.e. if you throw a ' 6 ', you get your chosen item but no money and if you throw any other number you get your chosen item plus the $£ 1,929$ left after repaying the loan)

19) $\square$ no insurance

(i.e. if you throw a ' 6 ' you get nothing and if you throw any other number you get your chosen item plus the $£ 2,500$ left after repaying the loan)

\section{insurance which increases the loan repayment by $£ 800$}

(i.e. if you throw a '6', you get your chosen item but no money and if you throw any other number you get your chosen item plus the $£ 1,700$ left after repaying the loan)

20) $\square$ no insurance

(i.e. if you throw a ' 6 ' you get nothing and if you throw any other number you get your chosen item plus the $£ 2,500$ left after repaying the loan)

$\square$ insurance which increases the loan repayment by $£ 1,000$

(i.e. if you throw a '6', you get your chosen item but no money and if you throw any other number you get your chosen item plus the $£ 1,500$ left after repaying the loan)

21) $\square$ no insurance

(i.e. if you throw a ' 6 ' you get nothing and if you throw any other number you get your chosen item plus the $£ 2,500$ left after repaying the loan)

insurance which increases the loan repayment by $£ 1,333$

(i.e. if you throw a ' 6 ', you get your chosen item but no money and if you throw any other number you get your chosen item plus the $£ 1,167$ left after repaying the loan)

Now throw the die.

Outcome of throwing the die:

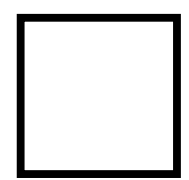




\section{Sheet 3}

Please tick ONE of the boxes for EACH question indicating your choice.

17) $\square$ no insurance

(i.e. if you throw a ' 6 ' you get nothing and if you throw any other number you get your chosen item plus the $£ 2,500$ left after repaying the loan)

\section{insurance which increases the loan repayment by $£ 500$}

(i.e. if you throw a ' 6 ', you get your chosen item but no money and if you throw any other number you get your chosen item plus the $£ 2,000$ left after repaying the loan)

18) $\square$ no insurance

(i.e. if you throw a ' 6 ' you get nothing and if you throw any other number you get your chosen item plus the $£ 2,500$ left after repaying the loan)

$\square$ insurance which increases the loan repayment by $£ 643$

(i.e. if you throw a ' 6 ', you get your chosen item but no money and if you throw any other number you get your chosen item plus the $£ 1,857$ left after repaying the loan)

19) $\square$ no insurance

(i.e. if you throw a ' 6 ' you get nothing and if you throw any other number you get your chosen item plus the $£ 2,500$ left after repaying the loan)

\section{insurance which increases the loan repayment by $£ 900$}

(i.e. if you throw a '6', you get your chosen item but no money and if you throw any other number you get your chosen item plus the $£ 1,600$ left after repaying the loan)

20) $\square$ no insurance

(i.e. if you throw a ' 6 ' you get nothing and if you throw any other number you get your chosen item plus the $£ 2,500$ left after repaying the loan)

$\square$ insurance which increases the loan repayment by $£ 1,125$

(i.e. if you throw a ' 6 ', you get your chosen item but no money and if you throw any other number you get your chosen item plus the $£ 1,375$ left after repaying the loan)

21) $\square$ no insurance

(i.e. if you throw a ' 6 ' you get nothing and if you throw any other number you get your chosen item plus the $£ 2,500$ left after repaying the loan)

insurance which increases the loan repayment by $£ 1,500$

(i.e. if you throw a ' 6 ', you get your chosen item but no money and if you throw any other number you get your chosen item plus the $£ 1,000$ left after repaying the loan)

Now throw the die.

Outcome of throwing the die:

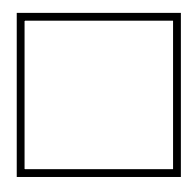




\section{Sheet 3}

Please tick ONE of the boxes for EACH question indicating your choice.

17) $\square$ no insurance

(i.e. if you throw a '6' you get nothing and if you throw any other number you get your chosen item plus the $£ 2,500$ left after repaying the loan)

\section{insurance which increases the loan repayment by $£ 556$}

(i.e. if you throw a ' 6 ', you get your chosen item but no money and if you throw any other number you get your chosen item plus the $£ 1,944$ left after repaying the loan)

18) $\square$ no insurance

(i.e. if you throw a ' 6 ' you get nothing and if you throw any other number you get your chosen item plus the $£ 2,500$ left after repaying the loan)

$\square$ insurance which increases the loan repayment by $£ 714$

(i.e. if you throw a ' 6 ', you get your chosen item but no money and if you throw any other number you get your chosen item plus the $£ 1,786$ left after repaying the loan)

19) $\square$ no insurance

(i.e. if you throw a ' 6 ' you get nothing and if you throw any other number you get your chosen item plus the $£ 2,500$ left after repaying the loan)

\section{insurance which increases the loan repayment by $£ 1,000$}

(i.e. if you throw a '6', you get your chosen item but no money and if you throw any other number you get your chosen item plus the $£ 1,500$ left after repaying the loan)

20) $\square$ no insurance

(i.e. if you throw a ' 6 ' you get nothing and if you throw any other number you get your chosen item plus the $£ 2,500$ left after repaying the loan)

$\square$ insurance which increases the loan repayment by $£ 1,250$

(i.e. if you throw a '6', you get your chosen item but no money and if you throw any other number you get your chosen item plus the $£ 1,250$ left after repaying the loan)

21) $\square$ no insurance

(i.e. if you throw a ' 6 ' you get nothing and if you throw any other number you get your chosen item plus the $£ 2,500$ left after repaying the loan)

insurance which increases the loan repayment by $£ 1,667$

(i.e. if you throw a ' 6 ', you get your chosen item but no money and if you throw any other number you get your chosen item plus the $£ 833$ left after repaying the loan)

Now throw the die.

Outcome of throwing the die:

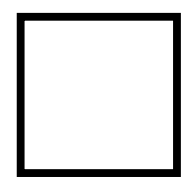




\section{Sheet 3}

Please tick ONE of the boxes for EACH question indicating your choice.

17) $\square$ no insurance

(i.e. if you throw a '6' you get nothing and if you throw any other number you get your chosen item plus the $£ 2,500$ left after repaying the loan)

\section{insurance which increases the loan repayment by $£ 611$}

(i.e. if you throw a ' 6 ', you get your chosen item but no money and if you throw any other number you get your chosen item plus the $£ 1,889$ left after repaying the loan)

18) $\square$ no insurance

(i.e. if you throw a ' 6 ' you get nothing and if you throw any other number you get your chosen item plus the $£ 2,500$ left after repaying the loan)

$\square$ insurance which increases the loan repayment by $£ 786$

(i.e. if you throw a ' 6 ', you get your chosen item but no money and if you throw any other number you get your chosen item plus the $£ 1,714$ left after repaying the loan)

19) $\square$ no insurance

(i.e. if you throw a ' 6 ' you get nothing and if you throw any other number you get your chosen item plus the $£ 2,500$ left after repaying the loan)

insurance which increases the loan repayment by $£ 1,100$

(i.e. if you throw a '6', you get your chosen item but no money and if you throw any other number you get your chosen item plus the $£ 1,400$ left after repaying the loan)

20) $\square$ no insurance

(i.e. if you throw a '6' you get nothing and if you throw any other number you get your chosen item plus the $£ 2,500$ left after repaying the loan)

$\square$ insurance which increases the loan repayment by $£ 1,375$

(i.e. if you throw a ' 6 ', you get your chosen item but no money and if you throw any other number you get your chosen item plus the $£ 1,125$ left after repaying the loan)

21) $\square$ no insurance

(i.e. if you throw a ' 6 ' you get nothing and if you throw any other number you get your chosen item plus the $£ 2,500$ left after repaying the loan)

insurance which increases the loan repayment by $£ 1,833$

(i.e. if you throw a ' 6 ', you get your chosen item but no money and if you throw any other number you get your chosen item plus the £667 left after repaying the loan)

Now throw the die.

Outcome of throwing the die:

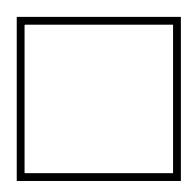




\section{Sheet 3}

Please tick ONE of the boxes for EACH question indicating your choice.

17) $\square$ no insurance

(i.e. if you throw a '6' you get nothing and if you throw any other number you get your chosen item plus the $£ 2,500$ left after repaying the loan)

\section{insurance which increases the loan repayment by $£ 667$}

(i.e. if you throw a ' 6 ', you get your chosen item but no money and if you throw any other number you get your chosen item plus the $£ 1,833$ left after repaying the loan)

18) $\square$ no insurance

(i.e. if you throw a ' 6 ' you get nothing and if you throw any other number you get your chosen item plus the $£ 2,500$ left after repaying the loan)

$\square$ insurance which increases the loan repayment by $£ 857$

(i.e. if you throw a ' 6 ', you get your chosen item but no money and if you throw any other number you get your chosen item plus the $£ 1,643$ left after repaying the loan)

19) $\square$ no insurance

(i.e. if you throw a ' 6 ' you get nothing and if you throw any other number you get your chosen item plus the $£ 2,500$ left after repaying the loan)

insurance which increases the loan repayment by $£ 1,200$

(i.e. if you throw a ' 6 ', you get your chosen item but no money and if you throw any other number you get your chosen item plus the $£ 1,300$ left after repaying the loan)

20) $\square$ no insurance

(i.e. if you throw a '6' you get nothing and if you throw any other number you get your chosen item plus the $£ 2,500$ left after repaying the loan)

$\square$ insurance which increases the loan repayment by $£ 1,500$

(i.e. if you throw a ' 6 ', you get your chosen item but no money and if you throw any other number you get your chosen item plus the $£ 1,000$ left after repaying the loan)

21) $\square$ no insurance

(i.e. if you throw a ' 6 ' you get nothing and if you throw any other number you get your chosen item plus the $£ 2,500$ left after repaying the loan)

insurance which increases the loan repayment by $£ 2,000$

(i.e. if you throw a ' 6 ', you get your chosen item but no money and if you throw any other number you get your chosen item plus the £500 left after repaying the loan)

Now throw the die.

Outcome of throwing the die:

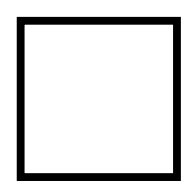




\section{Sheet 3}

Please tick ONE of the boxes for EACH question indicating your choice.

17) $\square$ no insurance

(i.e. if you throw a ' 6 ' you get nothing and if you throw any other number you get your chosen item plus the $£ 2,500$ left after repaying the loan)

$\square$ insurance which increases the loan repayment by $£ 722$

(i.e. if you throw a ' 6 ', you get your chosen item but no money and if you throw any other number you get your chosen item plus the $£ 1,778$ left after repaying the loan)

18) $\square$ no insurance

(i.e. if you throw a ' 6 ' you get nothing and if you throw any other number you get your chosen item plus the $£ 2,500$ left after repaying the loan)

$\square$ insurance which increases the loan repayment by $£ 929$

(i.e. if you throw a ' 6 ', you get your chosen item but no money and if you throw any other number you get your chosen item plus the $£ 1,571$ left after repaying the loan)

19) $\square$ no insurance

(i.e. if you throw a ' 6 ' you get nothing and if you throw any other number you get your chosen item plus the $£ 2,500$ left after repaying the loan)

\section{insurance which increases the loan repayment by $£ 1,300$}

(i.e. if you throw a ' 6 ', you get your chosen item but no money and if you throw any other number you get your chosen item plus the $£ 1,200$ left after repaying the loan)

20) $\square$ no insurance

(i.e. if you throw a ' 6 ' you get nothing and if you throw any other number you get your chosen item plus the $£ 2,500$ left after repaying the loan)

$\square$ insurance which increases the loan repayment by $£ 1,625$

(i.e. if you throw a ' 6 ', you get your chosen item but no money and if you throw any other number you get your chosen item plus the £875 left after repaying the loan)

21) $\square$ no insurance

(i.e. if you throw a ' 6 ' you get nothing and if you throw any other number you get your chosen item plus the $£ 2,500$ left after repaying the loan)

insurance which increases the loan repayment by $£ 2,167$

(i.e. if you throw a ' 6 ', you get your chosen item but no money and if you throw any other number you get your chosen item plus the $£ 333$ left after repaying the loan)

Now throw the die.

Outcome of throwing the die:

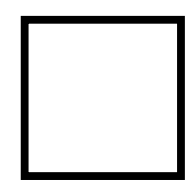




\section{Appendix C}

Table C1 provides summary statistics on the general demographic, personality and lifestyle characteristics of the buyers. Table C2 shows some financial characteristics of buyers and Table C3 summarizes buyers' views related to the experiment. Table C4 provides characteristics of sellers and Table C5 shows our questions on personality traits.

Table C1 General characteristics of buyers ${ }^{1}$

Gender

Male

Female

Age

Marital status

Single 54

Married

108

living as married

36

Divorced 15

Widowed

Social class
103

111

40.43

11.66

${ }^{1} \mathrm{O}$ levels (later replaced by GCSE) are a national school examination taken at around 16 and A levels are taken at about 18. The definition of social class is below.

\begin{tabular}{|c|c|c|}
\hline $\begin{array}{l}\text { social } \\
\text { grade }\end{array}$ & social status & Occupation \\
\hline A & $\begin{array}{l}\text { upper middle } \\
\text { class }\end{array}$ & higher managerial, administrative or professional \\
\hline B & middle class & intermediate managerial, administrative or professional \\
\hline C1 & $\begin{array}{l}\text { lower middle } \\
\text { class }\end{array}$ & supervisory or clerical, junior managerial, administrative or professional \\
\hline C2 & $\begin{array}{l}\text { skilled working } \\
\text { class }\end{array}$ & skilled manual workers \\
\hline D & working class & semi and unskilled manual workers \\
\hline $\mathbf{E}$ & $\begin{array}{l}\text { those at lowest } \\
\text { level of } \\
\text { subsistence }\end{array}$ & state pensioners or widows (no other earner), casual or lowest grade workers \\
\hline
\end{tabular}




\begin{tabular}{lc}
\hline \hline A & 0 \\
B & 24 \\
C1 & 87 \\
C2 & 59 \\
D & 44 \\
E & 0 \\
& \\
Academic qualification & 128 \\
O level or equivalent & 59 \\
A levels & 35 \\
University degree & 25 \\
Post graduate degree & \\
& \\
Employment status & 150 \\
full time (>16 hrs) & 48 \\
part-time & 5 \\
self employed & 8 \\
Retired & \\
\hline \hline
\end{tabular}

Table C2 Financial characteristics of buyers

Financial sophistication

High

Middle

Low

Income

Wealth (93 observations)

Mortgage holders

Mortgage holders with MPI

Loan holders (unsecured)

Loan holders with payment protection

Currently considering taking out a loan
26

113

75

20,325.52

$14,369.09$

$114,435.50$

$83,365.95$
124

61

79

31

214 
Table C3 Views on the experiment stated by buyers

Table C4 Characteristics of sellers

Gender

Male

Female

Age

Social class

$\begin{array}{lc}\text { A } & 0 \\ \text { B } & 3 \\ \text { C1 } & 22 \\ \text { C2 } & 0 \\ \text { D } & 0 \\ \text { E } & 0\end{array}$

Employment status

full time (>16 hrs) 20

part-time 4

self employed 1

Retired 0 
Financial sophistication

$\begin{array}{lc}\text { High } & 3 \\ \text { Middle } & 22 \\ & \end{array}$

Fulfilled a sales role in the last 5 years

Table C5 Questions on personality traits answered on a 6 item Likert scale

"I see myself as someone who..."

\begin{tabular}{|c|c|}
\hline Q1 & “... is reserved" \\
\hline Q2 & “... is generally trusting” \\
\hline Q3 & “... tends to be lazy” \\
\hline Q4 & “... is relaxed, handles stress well” \\
\hline Q5 & “... has few artistic interests” \\
\hline Q6 & “... is outgoing, sociable” \\
\hline Q7 & “... tends to find fault with others” \\
\hline Q8 & “... does a thorough job” \\
\hline Q9 & “... gets nervous easily” \\
\hline Q10 & “... has an active imagination” \\
\hline Q11 (10 point scale) & “I have a tendency to worry” \\
\hline
\end{tabular}

The questions on personality traits are taken from Rammstedt and John (2007). 